\title{
On the Synergy between Virtual Reality and Multi-Agent Systems
}

\author{
Alejandra Ospina-Bohórquez ${ }^{1, *,+} \mathbb{D}$, Sara Rodríguez-González ${ }^{1,+} \mathbb{D}$ and Diego Vergara-Rodríguez ${ }^{2,+}+\mathbb{D}$ \\ 1 Department of Computer Science and Automation, Faculty of Science, University of Salamanca, \\ Plaza de los Caídos s/n, 37008 Salamanca, Spain; srg@usal.es \\ 2 Department of Mechanical Engineering, Catholic University of Ávila, C/Canteros, s/n, 05005 Avila, Spain; \\ diego.vergara@ucavila.es \\ * Correspondence: ale.ospina15@usal.es \\ + These authors contributed equally to this work.
}

check for updates

Citation: Ospina-Bohórquez, A.;

Rodríguez-González, S.;

Vergara-Rodríguez, D. On the Synergy between Virtual Reality and Multi-Agent Systems. Sustainability 2021, 13, 4326. https://doi.org/ $10.3390 /$ su13084326

Academic Editor: Bilal Farooq

Received: 17 March 2021

Accepted: 10 April 2021

Published: 13 April 2021

Publisher's Note: MDPI stays neutral with regard to jurisdictional claims in published maps and institutional affiliations.

Copyright: (C) 2021 by the authors. Licensee MDPI, Basel, Switzerland. This article is an open access article distributed under the terms and conditions of the Creative Commons Attribution (CC BY) license (https:// creativecommons.org/licenses/by/ $4.0 /)$.

\begin{abstract}
Multi-agent systems integrate a great variety of artificial intelligence techniques from different fields, these systems have made it possible to create intelligent systems more efficiently. On the other hand, virtual reality applications are accepted as viable techniques in different areas such as visualization, simulation, design, and research. The combined use of these two technologies has led to the development of realistic and interactive applications. This work aims to do a Systematic Mapping Study (SMS) relying on the guidelines of Kitchenham and Petersen to analyze the state of the art of VR applications using multi-agent systems. Inclusion and exclusion criteria have been applied to identify relevant papers, 82 articles were selected and categorized according to the publication type, the research type, the asset type, and the purpose of the work. A complete review of the 82 selected articles was performed, based on the research questions that were established. This review made it possible to clarify the open lines of research that exist and to know where research in this field can be directed.
\end{abstract}

Keywords: virtual reality; multi-agent systems; systematic mapping study

\section{Introduction}

In recent years, multi-agent systems (MAS) have gained strength, systems that integrate a great variety of Artificial Intelligence techniques from different fields (reasoning, knowledge representation, machine learning, planning, coordination, communication, etc.) These systems have made it possible to create intelligent systems more efficiently and naturally, allowing them to solve complex problems of the real world [1-5].

A complex system can be decomposed into components, these into sub-components, and thus successively until some primitive entities are obtained. These entities can be seen as agents that solve local problems and interact with other agents, so they can achieve the system's objectives [1]. An agent is an autonomous and adaptive entity capable of communicating and taking action [6]. According to Balaji et al. [7] some important characteristics that differentiate an agent from a simple controller are:

- Situatedness: interaction between an agent and the environment through sensors and the resulting actions of the actuators.

- Autonomy: the ability of an agent to make its decisions about its actions independently without any external intervention.

- Inferential capacity: the ability of an agent to perform its tasks on abstract objective specifications.

- Responsiveness: ability to perceive the environment and respond taking into account any changes that may occur in the environment.

- Pro-activeness: agents must display opportunistic behaviors in which actions are aimed at achieving a goal rather than simply being actions in response to a change in the environment. 
- Social behavior: although the agent's decisions must be free from any external intervention, they must be able to interact with external sources when the situation requires it to achieve their objectives.

A MAS is a system composed of agents, in most cases these agents are computational processes (the agents can be distributed on different computers), but they also could be a robot, a human, etc. In a multi-agent system, a group of autonomous agents acts in an environment to accomplish an objective, which is achieved by cooperating or competing, sharing or not sharing knowledge among them.

For example, imagine that you want to simulate the situation in which a group of predators (a pack of wolves) is trying to hunt prey (a moose). In a MAS, each wolf in the pack and the moose are represented as agents with abilities and objectives. The wolf agents must be able to interact with their environment to decide which is the best way to achieve their objective (hunting the moose) but they must also be able to interact with the rest of the members of the pack. The moose agent, for his part, must also interact with his environment to know which way to take so as not to be reached and remain safe (for example, crossing a river that it knows that wolves cannot cross).

On the other hand, in recent times there has been a boom in the development and use of virtual reality (VR) applications [8-10]. In the beginning, 3D virtual environments were used almost exclusively for military purposes, however, lately, a new software tool to develop virtual 3D environments called game engine has been developed. These can maintain high visual quality and allow high interactivity with the user [11] while the environment is being built.

With virtual reality, the user is placed in a scene (sometimes as close as possible to reality) where he/she can interact with the objects in it. Nowadays, this technology is mostly used for videogames development, nevertheless, it also has begun to be used in many other fields (education [8,9], architecture [12,13], engineering [14], medicine [15], emergency services [16], tourism [17], marketing [18], etc.).

Today, VR is accepted as a viable technique in different areas such as visualization, simulation, design, and research. Virtual reality enables the user to interact with a threedimensional scenario where the reality that is simulated may not be accessible to users in the real world due to being dangerous or physically inaccessible $[19,20]$.

Nowadays, the combined use of these two technologies has led to the development of increasingly realistic and interactive applications in different areas such as videogames [21], education [6], or human behavior [21-23].

Taking this into account, it can be said that the use of VR combined with multi-agent systems makes available to anyone a useful and safe environment for the development of different practices without incurring costly testing, and also allows the development of powerful and versatile applications, useful in countless fields.

This work aims to analyze the state of the art of VR applications using multi-agent systems. Systematic mapping study (SMS) methodology was used, relying on the guidelines given by Kietchenham et al. [24] and Petersen et al. [25]. Thanks to this kind of study, it is possible to categorize existing studies in a specific research area through a scheme and structure indicating the frequency in which an investigation is carried out in the area $[26,27]$.

\section{Methods}

A SMS based on the methodology and process proposed by Kitchenham et al. [24] and Petersen et al. [25] is implemented in this paper. Furthermore, an investigation following this methodology will be carried out. The procedure will consist of three phases: Planning, Development, and Report. 


\subsection{Planning}

Using as reference the work of Kitchenham et al. [24], Petersen et al. [25], and SittónCandanedo et al. [27], three activities were included within the planning phase: motivation, objective, and research questions.

\subsubsection{Motivation}

The motivation for this Systematic Mapping Study is to get a general idea of the evolution of the use of MAS in Virtual Reality applications in different fields. The main objective of this research is to review the state of the art of studies that propose the combined use of multi-agent systems and VR to provide new and more effective solutions in different areas. Likewise, it is intended to find new lines of research in the area of MAS and VR.

\subsubsection{Objective}

In recent times, it has been seen that the use of MAS in different fields allows the creation of more complete and efficient applications. On the other hand, Virtual Reality has been gaining importance thanks to the fact that it allows simulating situations that if done in real life can be dangerous or/and expensive. Besides, it appreciates the great functionality that the multi-agent systems provide in VR applications in different areas such as education, human behavior, staff training, videogames, etc. Due to the importance that both MAS and VR have gained, the prime objective of this research is to identify the trend, evolution, and main research on the use of multi-agent systems within virtual reality applications, so that a fairly comprehensive view of current research on MAS and VR is obtained.

\subsubsection{Research Questions}

The research questions used as the basis for the Systematic mapping study are:

- What applications have been developed with Multi-agent systems in the field of Virtual reality?

- How does Virtual Reality benefit from the use of Multi-agent systems?

Answering these questions will allow categorizing the works found up to 18 November 2020, and present the results obtained in Section 3.

\subsection{Development of the Study}

During the development of the study, all the tasks associated with the SMS will be performed in this phase. As in the article of Sittón-Candanedo et al. [27], both the strategy and the study's inclusion and exclusion criteria must be established.

\subsubsection{Search Strategy}

The Search strategy refers to the establishment of search guidelines to conduct the study. Population, Intervention, Comparison, and Outcomes (PICO), proposed by Kitchenham et al. [28], was chosen as a search strategy. This strategy was developed to identify keywords and formulate search guidelines taking into account the research questions [25]:

- Population: everything that the study covers, in this case, research articles.

- Intervention: refers to the methods, models, architectures, etc. of MAS that are used within VR solutions.

- Comparison: a comparison of the different solutions find during the process.

- Outcomes: not applicable to this SMS.

After applying the PICO search strategy, the keywords that were initially considered for the database search were Virtual Reality and Multi-agent systems. However, to increase the results obtained during the search, other keywords were also included: Multi-agent architecture, 3D application, 3D model, and 3D simulation (Figure 1). The Web of Science and Scopus were used for the research and the deadline for the article search was 18 November 
2020. In Table 1 search strings are detailed, for each database, three search strings were created thinking of maximizing the number of works obtained in the preliminary results.

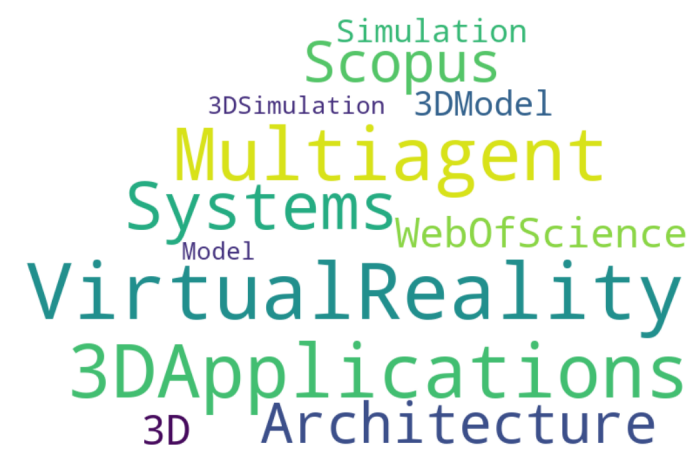

Figure 1. Keywords and databases used in this research work.

Table 1. Search strings used.

\begin{tabular}{|c|c|}
\hline Database & Search String \\
\hline Web of Science (WoS1) & $\begin{array}{l}(\mathrm{TS}=(\text { virtual reality AND multi-agent systems)) Bases de } \\
\text { datos=WOS, CCC, DIIDW, KJD, MEDLINE, RSCI, SCIELO }\end{array}$ \\
\hline Web of Science (WoS2) & $\begin{array}{l}\text { Período de tiempo=2016-2020 Idioma de búsqueda=Auto } \\
\text { (TS=((virtual reality OR 3D applications OR 3D model OR 3D } \\
\text { simulation) AND multi-agent systems)) Bases de datos=WOS, } \\
\text { CCC, DIIDW, KJD, MEDLINE, RSCI, SCIELO Período de } \\
\text { tiempo=2016-2020 Idioma de búsqueda=Auto }\end{array}$ \\
\hline Web of Science (WoS3) & $\begin{array}{l}\text { (TS= }=((\text { virtual reality OR 3D applications OR 3D model OR } \\
\text { 3D simulation) AND (multi-agent systems OR multi-agent } \\
\text { architecture)) Bases de datos=WOS, CCC, DIIDW, KJD, MED- } \\
\text { LINE, RSCI, SCIELO Período de tiempo=2016-2020 Idioma de } \\
\text { búsqueda=Auto }\end{array}$ \\
\hline Scopus (S1) & $\begin{array}{l}\text { TITLE-ABS-KEY (“virtual reality” AND "multi-agent sys- } \\
\text { tems") AND PUBYEAR > } 2015\end{array}$ \\
\hline Scopus (S2) & $\begin{array}{l}\text { TITLE-ABS-KEY ((“virtual reality" OR “3D applications" OR } \\
\text { "3D model" OR “3D simulation" ) AND "multi-agent systems") } \\
\text { AND PUBYEAR > } 2015\end{array}$ \\
\hline Scopus (S3) & $\begin{array}{l}\text { TITLE-ABS-KEY ((“virtual reality" OR “3D applications" OR } \\
\text { "3D model" OR “3D simulation") AND ("multi-agent systems" } \\
\text { OR "multi-agent architecture")) AND PUBYEAR > } 2015\end{array}$ \\
\hline
\end{tabular}

\subsubsection{Inclusion and Exclusion Criteria}

Regarding the inclusion and exclusion criteria, according to the guidelines set by Petersen et al. [25], it is important to establish the characteristics that the selected studies must have to be included or excluded from the SMS. Using this guide and the SMS developed by Sittón-Candenado et al. [27], the following inclusion and exclusion criteria were considered to select a paper:

- Inclusion criteria:

- IC1: Studies about multi-agent systems and virtual reality.

- IC2: Studies published between 2016 and 2020.

- IC3: Articles published in conferences or journals and peer-reviewed book chapters.

- Exclusion criteria:

- EC1: Duplicated papers.

- $\quad$ EC2: Papers that do not address the topic of MAS and VR.

- EC3: Papers in which the authors doubt whether there were contributions to the field or not. 
- EC4: Papers that are not in English or Spanish.

\subsection{Report}

To make this study a complete work, the report includes an outline of the information extracted, which includes the asset and the type of investigation. While the study filtering process was being performed, there were doubts about the relevance and / or fit of 43 studies within this SMS. To solve this issue, the other authors were asked about these studies, and from this discussion, it was decided whether or not a study should be included, this was an iterative process that was carried out in different stages of the filtering of studies.

\subsubsection{Filtering Studies}

In the first phase, a total of 572 studies were found. The process of filtering studies applying the aforementioned inclusion and exclusion criteria was carried out by the first author. In case it was not clear, the other authors were consulted if a paper should be included or excluded.

\subsubsection{Classification Process}

Taking as reference the work of Sittón-Candanedo et al. [27], when the filtering process has been concluded, the papers obtained were classified taking into account the following categories: Author, Title, Year, Publication type, Research type, and Asset type. The Publication type can be a Journal article, a Conference article, or a Book chapter. The Research type can be Conceptual, Experimental, or Validation, being non-exclusive so that a study can be classified into different types. In the Asset type category, it is intended to determine the main contribution of a work: Model, Framework, Architecture, Platform, etc. As in the previous category, the types are not exclusive. The results of this work can be seen in Appendix A.

\subsubsection{Validation Process}

For the validation of Systematic Mapping Studies, Petersen et al. [25] established guidelines that indicated a series of activities that should be accomplished when performing a study of this type. This evaluation consists of 26 activities that should be performed when conducting an SMS, also, it is indicated that a well-developed SMS must carry out at least $33 \%$ of the activities. Taking into account this validation system, it is necessary to calculate the relation between the number of activities and the 26 activities proposed by Petersen et al. to measure the validity of an SMS. Taking as an example the SMS conducted by Sitton-Cadenado et al. [27], we elaborated the Table 2 where it is seen the mapping phases (Planning, Development, and Report) along with the activities that were executed (based on Petersen's guidelines) to ensure the validity of our study, 16 activities were performed, constituting $61 \%$ of the total, an amount that allows us to say that it is a well-developed SMS. 
Table 2. Evaluation realized in this systematic mapping study (SMS), taking into account the guidelines proposed by Petersen et al. [25]

\begin{tabular}{|c|c|c|c|c|}
\hline & Research Process & & $\begin{array}{l}\text { Applied } \\
(\text { Yes }=\checkmark, \text { No }=x)\end{array}$ & Defined in: \\
\hline \multirow{3}{*}{ Planning } & \multirow{3}{*}{ Need for the map } & 1. Motivate the need and relevance & $\checkmark$ & Introduction (1), Motivation (Section 2.1.1), Discussion (Section 4) \\
\hline & & 2. Define objective and questions & $\checkmark$ & \multirow[t]{2}{*}{ Objective (Section 2.1.2), Research Questions (Section 2.1.3) } \\
\hline & & 3. Consult with target audience to define questions & $x$ & \\
\hline \multirow{14}{*}{ Development } & \multirow{3}{*}{ Choosing search strategy } & 4. Snowballing & $x$ & \multirow[b]{3}{*}{ Search Strategy (Section 2.2.1), Results(Section 3) } \\
\hline & & 5. Manual search & $x$ & \\
\hline & & 6. Database search & $\checkmark$ & \\
\hline & \multirow{4}{*}{ Develop the search } & 7. PICO & $\checkmark$ & \multirow[t]{2}{*}{ Search Strategy (Section 2.2.1) } \\
\hline & & 8. Consult experts & $x$ & \\
\hline & & 10. Keywords from known papers & $\checkmark$ & Table 1 \\
\hline & & 11. Use standards, encyclopedias & $x$ & \multirow{5}{*}{ Validation process (Section 2.3.3) } \\
\hline & \multirow{4}{*}{ Search evaluation } & 12. Paper test-set & $\checkmark$ & \\
\hline & & 13. Expert evaluation & $x$ & \\
\hline & & 14. Author's web pages & $x$ & \\
\hline & & 15. Test-retest & $x$ & \\
\hline & \multirow{3}{*}{ Inclusion/Exclusion } & 16. Identify objective criteria for decision & $\checkmark$ & Search Strategy (2.2.1), Inclusion and Exclusion Criteria (2.2.2) \\
\hline & & 17. Resolve disagreements among multiple researchers & $\checkmark$ & Report (Section 2.3) \\
\hline & & 18. Decision rules & $\checkmark$ & Inclusion and Exclusion Criteria (Section 2.2.2) \\
\hline \multirow{6}{*}{ Report } & \multirow{2}{*}{ Extraction Process } & 19. Identify objective criteria for decision & $\checkmark$ & \multirow[t]{2}{*}{ Inclusion and Exclusion Criteria (Section 2.2.2) } \\
\hline & & 22. Test-retest & $x$ & \\
\hline & \multirow{3}{*}{ Classification scheme } & 23. Research type & $\checkmark$ & Methods (Section 2) \\
\hline & & 24. Research method & $\checkmark$ & Methods (Section 2) \\
\hline & & 25. Venue type & $\checkmark$ & Results (Section 3) \\
\hline & Validity and discussion & 26. Validity discussion / limitations provided & $\checkmark$ & Validation process (Section 2.3.3) \\
\hline
\end{tabular}




\section{Results}

This section includes the Systematic Mapping study report. As detailed above, Virtual Reality and Multi-agent Systems were used at first as keywords for searching in databases, both for Web of Science and Scopus, but to increase the number of works obtained, the search was extended using the keywords seen in Table 1 (the preliminary results per database are shown in Table 3), finally obtaining 572 studies that were reviewed and filtered applying the inclusion and exclusion criteria.

Table 3. Search strings used.

\begin{tabular}{cc}
\hline Database & Search String \\
\hline Web of Science (WoS1) & 171 \\
Web of Science (WoS2) & 296 \\
Web of Science (WoS3) & 299 \\
Scopus (S1) & 246 \\
Scopus (S2) & 272 \\
Scopus (S3) & 273 \\
\hline Total & 572 \\
\hline
\end{tabular}

This process of filtering studies is detailed in Figure 2, which includes the activities performed.

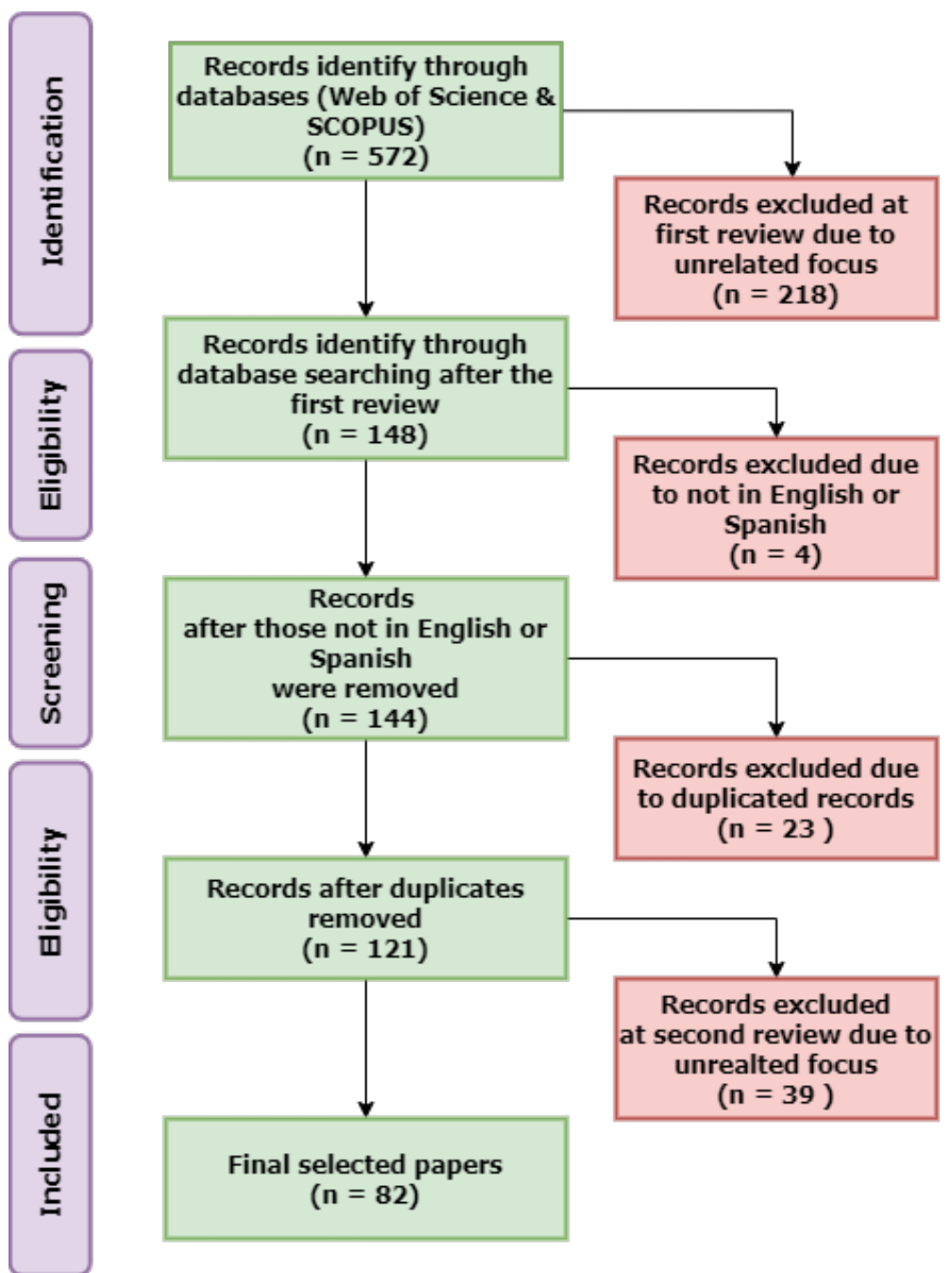

Figure 2. Flow chart illustrating the different phases of SMS. 
The results of the categorization of the works according to the Research type can be seen in Figure 3 and according to the Asset type in Figure 4.

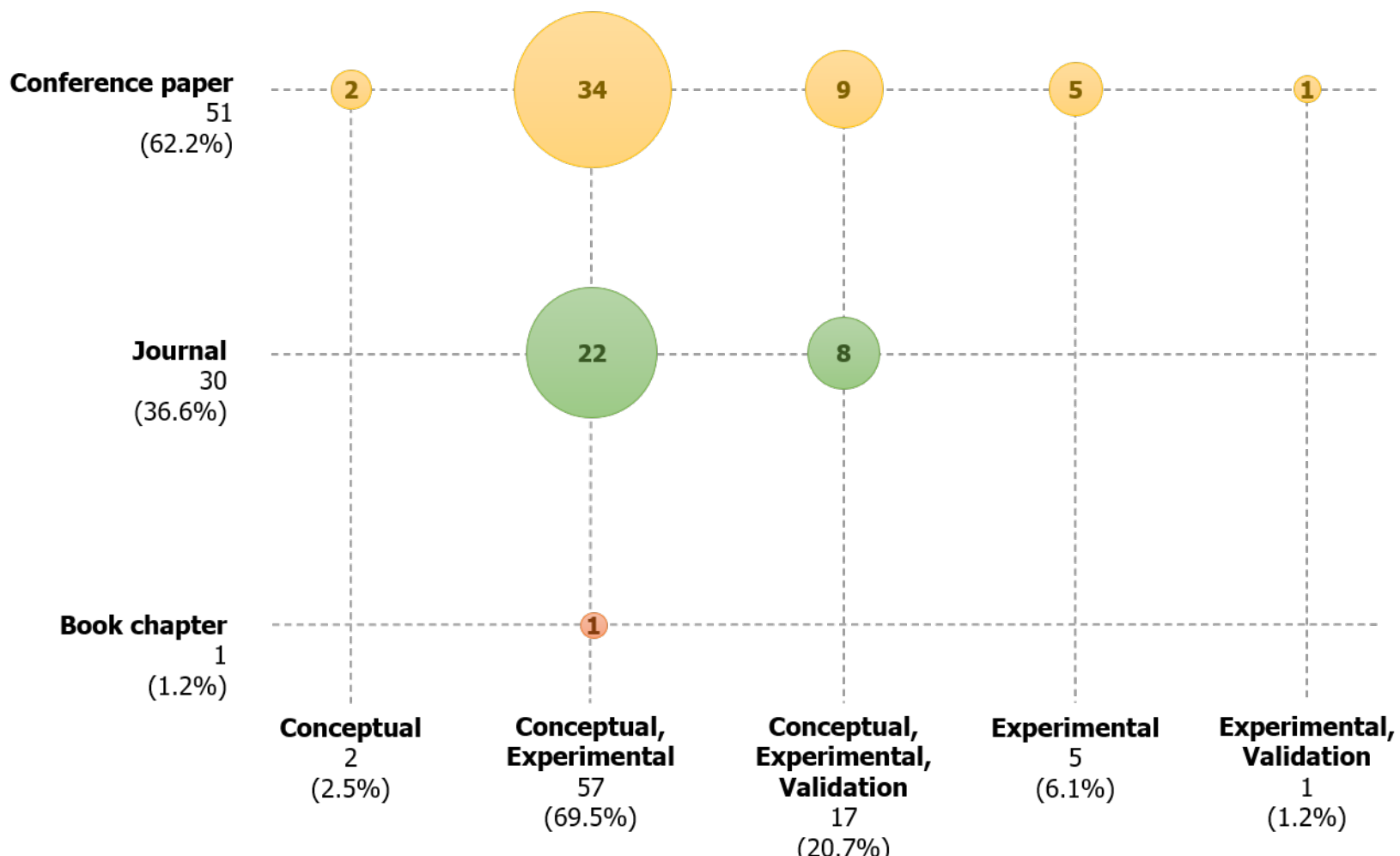

Figure 3. Classification of the works according to the Publication type and the Research type.

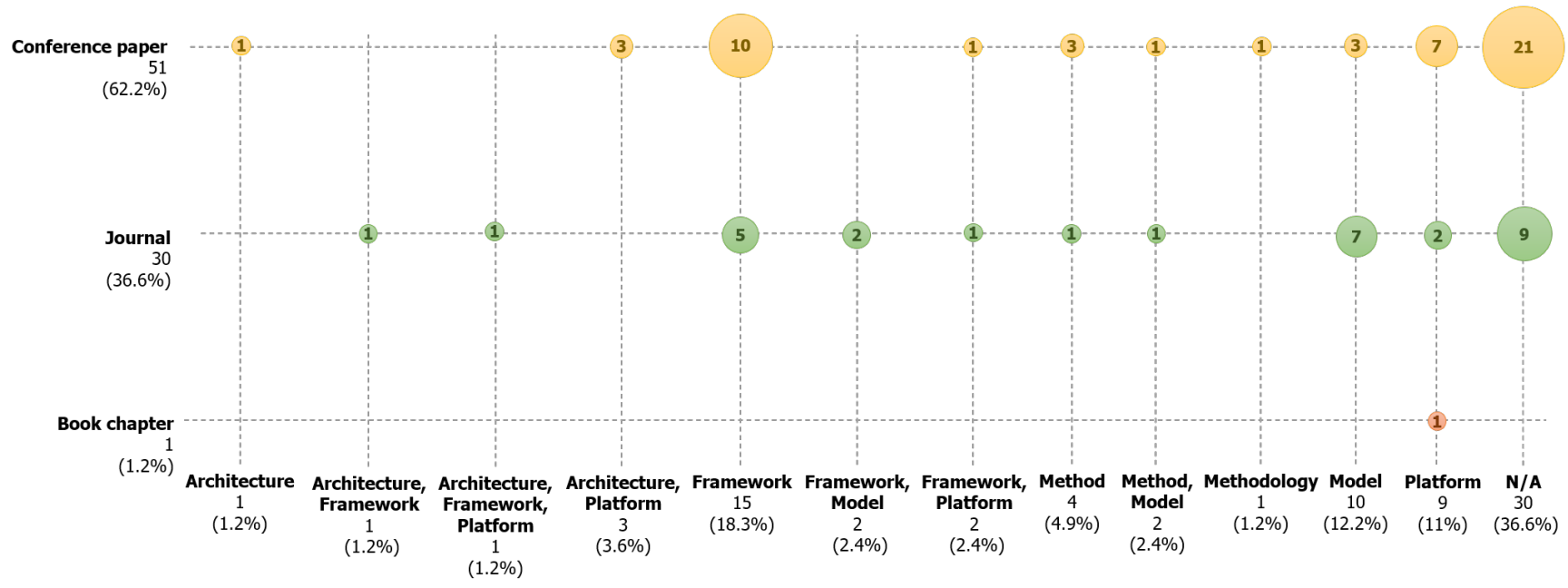

Figure 4. Classification of the works according to the Publication type and the Asset type.

As the SMS progressed, it became necessary and natural to carry out a new categorization based on the purpose of each of the works included in this study. This category will later allow making a classification that will be shown in the Discussion (Section 4). The works, according to the research carried out, may be directed to the development of videogames, the human behavior simulation, the dissemination of cultural heritage, urban planning, the development of autonomous vehicles, the machinery simulation, the development of intelligent virtual environments (IVEs) and robot simulation. 


\section{Discussion}

A SMS is a systematic review of the literature that aims to identify and categorize the research works available in a specific area [24,29]. The main goal of this type of study is to determine the scope of a specific research field, analyzing the frequency of publications in different categories in a schematic way [27].

In the field of computer science, at first, Systematic mapping studies were used mainly in the area of software engineering. These allowed researchers to reach a fairly comprehensive understanding of the field of study and helped to refine research questions and topics of interest [27]. Today, this type of study has begun to be used in more specific areas, as in this research work, which focuses on the use of multi-agent systems in virtual reality applications.

As the study progressed, it became very clear that the form of categorization of the works that had to be followed to capture the studies found was according to their purpose (Figure 5), then, taking into account the keywords and titles of each work, it was decided to do the following categorization: videogames development, robot simulation, interactive environment development, human behavior simulation, dissemination of cultural heritage, urban development, development of autonomous vehicles, and simulation of machinery. Some works have been identified and are presented below.

\subsection{Videogames}

As is known, the development of videogames using virtual reality has become quite popular in recent times, so it was to be expected to find studies in the field of VR and MAS that would get involved in videogames [30-36]. Within the area of virtual reality videogames, MAS are used to improve the user experience during the game. In the study of Lakshika et al. [30], it is proposed a multi-objective evolutionary framework to develop low-complexity, high fidelity MAS through the use of machine learning trained taking into account human aesthetic judgment to achieve a realistic animation of non-player characters (NPCs). García-Ortega et al. [31] proposed a three-layered system: evolutionary computation, agent-based model, and logical reasoner, that is applied to the promotion of the myth of the hero's journey to improve the experience of videogames users by creating more complex and interesting backstories. Narang et al. [32] developed a real-time algorithm based on a multi-agent simulation that allows inferring the intention of the user's avatar, it is intended to improve the response of virtual agents to make the experience more realistic and comfortable for the user.

On the other hand, in the study of Makarov et al. [33], a first-person shooter game with advanced and intelligent NPCs was presented, the authors developed an intelligent agent that derives its skills from the experience in the game and makes decisions through the same cognitive patterns as humans. Likewise, they created smart teams in which each player can make their own decisions under the supervision of an expert team goal system.

In the paper of Seele et al. [34], it was highlighted that populating virtual worlds with virtual agents with realistic behavior improves the user's sense of presence and therefore their experience inside those worlds. Taking this into account a framework for improving the user's synthetic perception is proposed, and another work of Seele et al. [35] also presented a framework to address this issue, the main objective of this framework is to achieve a natural behavior for the agents and to get real-time performance and controllability. There is also a framework proposed by Nunnari et al. [36] for the creation of real-time interactive virtual humans, it allows the deployment of new characters in a short time of work.

\section{Interactive Narratives}

Matthew et al. $[37,38]$ go beyond the subject of videogames and address the subject of Interactive Storytelling, specifically the way narrative agents are visualized in complex scenes. They proposed a framework to automate aspects of a staging of the activities of narrative agents and their interactions. Along the same lines, Porteous et al. [39] studied 
the use of interactive narratives to support psychology experiments in understanding stories. For this, they developed an interactive narrative generation mechanism that allows variations of the original story that facilitates the understanding of the story.

\subsection{Robots}

In the field of robot simulation, these technologies have also begun to be used, where the MAS agents serve as a representation of robots. Raza et al. [40] presented an imitationbased solution that learns a weighted Bayes structure, to learn collaborative strategies between multiple agents through imitation. The applicability of this approach was evaluated in the RoboCup Soccer 3D simulation environment.

Seghour et al. [41] investigated the control of multiple mobile robots based on a consensus approach, ensuring collision avoidance. For this, a consensus algorithm was developed, including a fuzzy logic system to calculate the translation and the angular velocity of the robot to maintain the formation and obtain the direction of the leading robot.

\subsection{Intelligent Virtual Environments (IVEs)}

For the development of IVEs, MAS have also been used within VR. Rincon et al. [42] presented the JaCalIVE framework design for the execution and adaptation of Intelligent Virtual Environments (IVEs). This framework is based on the MAM5 ontology (also proposed by Rincón et al. [43]) that describes the environment for MAS as populated not only by agents but also by other entities called artifacts. This ontology improves the knowledge representation characteristics and reasoning capabilities of an agent-based IVE. Continuing with this line, as an improvement of the previous ontology, Okreša et al. [44] proposed $\mathrm{MAMbO} 5$ ontology that allows all agents to reason and deal with the elements of the environment, and it is also integrated with the JaCalIVE framework.

Subagdja et al. [45] proposed a framework for the creation of interactive systems where the system components are considered autonomous agents that the user can configure. This framework allows non-expert users to configure all components at run time.

\subsection{Human Behavior}

Likewise, there are some studies in the field of human movement and behavior that combine both technologies [46-56]. Within this line, the field of crowd simulation has also gained strength, and we also find some studies on it using VR and MAS [57-68]. This type of simulation has multiple purposes: planning emergency plans [69-72], improvement of the work environment [73-78], improvement of the educational environment [79-86], people training [87-95], interactions between humans and avatars [96,97], smart buildings and commerce simulation [98,99], etc.

Narang et al. [46] proposed an algorithm called Body Aware Movement (BAM) to generate plausible movements for human-like agents. They integrated BAM with the Unreal game engine, so they could demonstrate the benefits of the algorithm generating agentagent and avatar-agent interactions. Likewise, Cafaro et al. [47] presented an interactive system for generating plausible non-verbal behaviors realized by virtual agents in a small group. Song et al. [48], for their part, proposed a form of simulation of individual behavior combining Geographical Information Science (GIS) and MAS, thus creating Grid Object and Agent Model (GOAM). In like manner, Starzyk et al. [49] presented the development of a motivated learning agent that is equipped with impulses and pains that establish their motivations to learn to respond to events and create related goals. This agent was implemented within a virtual environment to explore the autonomous development of motivations and memory in agents.

Bönsch et al. [50] devise a multi-agent system that models the transition between an anonymous and an individual agent when the user approaches.

Zhang et al. [51] proposed a form of simulation of virtual humans behaviors in built environments, in which task-based behaviors are simulated. They integrated the traditional approaches of behavior authoring frameworks into a single framework, which allows 
satisfying the temporal variation, the specification of the level occupancy of buildings, the distribution of the behavior in rooms, and the motivation of the agents. In the same manner, the objective of Puig et al. [52] is to model activities that occur at home, so it proposes to use programs as a high-level representation of complex tasks.

In the paper of Andelfinger et al. [53], it is proposed an incremental calibration of pedestrian models using virtual environments where computational agents and humancontrolled agents interact, with each calibration cycle, the computational agents adapt to previously observed human behavior. Bera et al. [54] emphasize that large and cohesive groups of people can be threatening to observers, therefore they propose an algorithm to predict the socio-emotional impact of these groups on observers. To validate this algorithm, they presented an interactive multi-agent simulation that models this type of group with VR.

Ranjbartabar et al. [55] investigated the usefulness of a virtual agent performing therapy on a user using the Emotional Freedom Technique (EFT) (psychological acupressure technique to optimize physical and mental health), comparing two types of therapeutic agents (one empathic and the other non-empathic).

Ohmoto et al. [56] proposed an agent behavior model that induces intentional stance in multiple to multiple human-agent interactions.

\subsubsection{Crowd Simulation}

On the other hand, Kim et al. [57] and Bera et al. [58] proposed a crowd simulation approach that combines data-driven methods with the interactivity of multi-agents techniques. Multi-agent models are used to change each individual's behavior in response to an external event such as an external stressor resulting in a panic situation. PhoneAmnuaisuk et al. [59] also proposed a form of crowd simulation with realistic animations for the agent's activities in a 3D environment. They used a multi-agent approach to simulate crowd movements, where an agent can perceive and interact with other agents and their environment.

To try to solve the problem of team-building with realistic crowd behaviors, Wang et al. [60] proposed a crowd formation framework through hierarchical planning (CFHP), consisting of three layers of automatic and intelligent planning: cooperative-task, coordination behavior, and action-control planning.

For their part, Agil et al. [61] proposed a model that allows virtual agents to produce plausible gaze behaviors within crowds, predicting the points of interest of the characters at each timestamp, the generated framework can be added as a plugin in game engines. Narang et al. [62] also presented an interactive approach to generate realistic movements for virtual agents, such as looking and gesturing and allowing a more natural interaction between humans and agents. Following this line, Novick et al. [63] presented a virtual reality scene where the user interacts with different virtual agents and initiates conversations with them either by approaching or gazing at them, likewise, the agent can initiate a conversation if the user approaches, a model was used for examining interpersonal distances. Likewise, Randhavane et al. [64] showed an approach to multi-agent navigation that facilitates face-to-face interaction between a user and a virtual agent that is part of a crowd. The authors described a model of approach behavior to predict if the user is approaching to have a face-to-face interaction or not, besides, they presented an interaction velocity prediction (IVP) algorithm that combines with the restrictions of movement of the human body and facial actions to improve the realism of the behavior.

Dickinson et al. [65] explored the impact of crowd density on a person's experience and behavior, for which they created an agent-based simulation using VR in which participants walk freely and perform some task while interacting with agents controlled by a social simulation model. A form of crowd simulation is also proposed by Montana et al. [66], it is suggested a way to control pedestrian real-time simulations in which non-expert users can interact with the simulation by creating actions and objects from the scene. 
Jayalath et al. [67], more than a form of crowd simulation, showed a form of simulation of individuals within a crowd, they presented an agent-based behavior model that simulates the decision-making abilities of individual characters within social groups in crowd simulations, including a decision function for each character to select the most appropriate target. Also, Chen et al. [68] proposed a system that simulates agents transporting objects in virtual environments with pedestrians. They proposed techniques to achieve different kinds of cooperation behaviors between agents in crowd simulations.

\subsubsection{Emergency Plans}

In the case of emergency plans, Yi Li et al. [69] studied the human environment during flooding and promoted a simulation model that combines cellular automata and a MAS to simulate crowd evacuations in flood disasters. The model proposed to integrate the evolution of water, land cover, objective domain, crowd, and individual movements data. For their part, Wang et al. [70] proposed a way to model the behavior characteristics of objects in a scene applying behavior tree and multi-agent model in-game artificial intelligence. The objective is to improve and serve as a guide for emergency plans and public safety deployments at different kinds of events.

Mao et al. [71] presented a form of simulations for emergency evacuations, also simulating emotional contagion in groups during these events. The authors presented an agent-based framework to simulate these evacuations in a virtual environment. Montecchiari et al. [72] also presented an agent-based evacuation tool that enables human interaction through immersive VR.

\subsubsection{Work Environment}

Barriuso et al. [73] proposed a multi-agent system called MOVICLOUD based on virtual organizations ( $\mathrm{VO}$ ), with the ability to perform social simulations in $3 \mathrm{D}$ environments. This study focuses on the integration of disabled people in workspaces, trying to improve the building's accessibility and adapting work processes so that they continue to be efficient while allowing these people integration. Also to improve the work environment, Zeng et al. [74] proposed a platform that simulates the activity of an office building to determine and improve sedentary lifestyle at work, it is believed that the improvement in the design of these buildings can promote an active and healthy workforce. Antakli et al. $[75,76]$ proposed a framework for the 3D simulation of hybrid equipment (robots, humans, etc.) in production scenarios to evaluate the critical properties of such scenarios and the assignment of tasks to team members. Antakli et al. [77] proposed an agent platform (HumanSim), a combination of Belief, Desire, Intention (BDI) paradigm and Answer Set Programming (ASP) to simulate worker agents in a shop floor domain. In the paper of Cai et al. [78], the use of an interactive virtual environment is proposed for the simulation of the behavior of miners inside an underground coal mine, for which a behavioral framework based on emotional states and motivational needs is proposed. The main objective of this system is to be able to simulate human behaviors that can generate accidents inside the mine.

\subsubsection{Educational Environment}

In the educational field, Calvo et al. [79] developed the Deployment Representation Model to work with MAS in immersive virtual environments systems applied to educational projects. Baierle et al. [80] proposed a logic programming environment with BDI and multi-agent concepts integrated with VR used to create an interactive virtual environment, focused on teaching the beginnings of Industrial Evolution. There is also a project proposed by Tazouti et al. [81] and Boulaknadel et al. [82], whose objective is Amazigh language learning in a virtual environment, using 3D serious games combine with MAS to improve interactivity.

Within this field, but aimed at teacher training, Nilsson et al. [83] proposed the simulation of human behavior but to train the gestures and body language of teachers in front 
of an audience. Therefore, they presented a MAS that uses the BDI model that emulates human behavior with a group of agents that would constitute a virtual audience. Likewise, Lugrin et al. [84] proposed a system for teacher training that simulates virtual classes with different levels of discipline. Their contribution was a method for the development and systematic evaluation of virtual human groups in VR and their ability to simulate specific atmospheres. In the same way, Barange et al. [85] proposed the design of an agent architecture for the generation of reactive, proactive, and pedagogical behaviors for agents. The project aims to support instructors as well as improve the learning experience for trainees. The proposed architecture is based on the BDI model and allows the coordination of activities between agents using communication in natural language. Moreover, Fukuda et al. [86] created a virtual classroom using VR where virtual students (agents) can interact through the atmosphere, then teachers can improve their class by taking into account this atmosphere.

\subsubsection{Training}

Within the scope of staff training, Blankendaal and Bosse [87] carried out a study which it is discussed how biofeedback can be shown and used in the context of virtual training based on social skills agents, it is simulated an adaptive scenario where the user interacts with a threatening virtual interlocutor. In the same sense, Feng et al. [88] intend to examine the effects of negative feedback on users, with virtual instructors, taking into account the gender and non-verbal behavior of those instructors. Johnson et al. [89] proposed a way to learn negotiation skills using virtual role-playing agents, they focused on the post-negotiation feedback, arguing that is the most crucial part of a training experience. They used an agent called Conflict Resolution Agent (CRA) that allows conversing with simulated negotiation partners.

Tavcar and Gams [90] proposed an approach in which the simulated agents are virtual copies of humans being trained. These agents were built and tested to provide feedback and decision support in future rounds of human learning. The objective of these simulations is to facilitate training in simulated environments dealing with both cooperative and adversarial agents.

Barthès et al. [91] discussed the design of training environments using a VR space to train medics to organize a medical post in a combat area so that all wounded can be treated efficiently. Also in the field of medicine, De Lima et al. [92] presented a complementary environment for teaching medicine in which clinical cases are simulated to evaluate the knowledge of the students, this system uses a MAS and machine learning for the disease classification of virtual patients. In the paper of Benkhedda et al. [93], to teach first aid in the event of cardiac arrest, serious games and multi-agent systems are combined to create an agent-based simulation that allows simulating this situation, integrating BDI agents into the NPCs.

In the article of Ooi et al. [94], a VR training system focused on fire prevention was proposed, it is said that VR provides an experience closer to reality. It uses different types of agents: fire smoke agent showing the details of the fire over time and indicating whether or not the player can evacuate, and student agent showing an agent occupying an area.

Tianwu et al. [95] proposed a travel training system for children with intellectual disabilities that would allow them to achieve a slightly more independent life. To simplify the interaction between all traffic entities and the virtual traffic environment, they implemented a MAS with a centralized data manager.

\subsubsection{Interactions between Humans and Avatars}

Best et al. [96] proposed an approach for generating realistic interactions between virtual agents and user avatars, they called it Sense-Plan-Ask (SPA) and enables virtual agents to achieve their individual goals with uncertain information in complex multiagent and multi-avatar environments. Braz et al. [97] described the development of a cognitive simulation game that integrates a group of agents that manage and monitor 
user performance as they move around the environment, the main goal is to improve the attention and memory of patients with neuropsychiatric disorders.

\subsubsection{Smart Buildings and Commerce}

Christian et al. [98] presented a prototype of a multi-agent simulation tool of a shopping center together with a fuzzy logic algorithm that uses the basic knowledge of the agents as input to determine the behavior of the agents in the system so that this behavior is the most realistic possible.

Zhao et al. [99] proposed a multi-agent human activity simulator for the development and evaluation of activity analysis algorithms in smart buildings. Their proposal integrates the Building Information Modeling (BIM) with Unity 3D where they simulate multiple agents with different abilities and tasks.

\subsection{Cultural Heritage}

3D simulations of human behavior have even been used for the dissemination of intangible cultural heritage as in the study of Vosinakis et al. [100], where the ancient agora of Athens is reconstructed in a virtual world and an interactive scenario is created, where user can see what life was like there at that time. They used MAS to simulate people's behaviors using NPCs and create a world where users can explore the environment, observed the activities performed by NPCs, and discuss with them to learn more about their life and customs.

On the other hand, Kiourt et al. [101] presented a framework for linking up Agents and Multi-agents Systems with virtual environments and cultural heritage.

\subsection{Urban Development}

Urban development also makes use of these two technologies because (i) it allows reducing costs when planning, designing, and building, (ii) it allows simulating different scenarios without putting anyone's life at risk, and (iii) it allows efficiently simulating different scenes.

Ren et al. [102] presented an approach that combines physics-based simulation with data-based techniques to compute trajectories and behaviors of entities, this approach can simulate heterogeneous agents such as human crowds, traffic, or vehicles.

Rivalcoba et al. [103] presented a system for simulate and visualize pedestrians inside urban environments, the system includes a MAS that assigns physical and psychological characteristics to the virtual agents.

Okamoto et al. [104] also proposed a virtual simulator that optimizes the design factors of a lane from the point of view of reducing pedestrian stress to reduce accidents in the bicycle and pedestrian lanes. Also, in the work of Chen et al. [105], VR is used for the operational simulation of urban rail traffic, it is required that pedestrians act realistically in the simulation, so this model was developed based on a multi-agent system that allows imitating the behavior of individuals and their interaction with the traffic system. For their part, Garg et al. [106] developed a tool for traffic simulation that, through an interactive environment, allows a rigorous simulation that is close to reality. The idea is that this simulation serves to carry out an implementation in the real world.

\subsection{Autonomous Vehicles}

Chen et al. [107] proposed a simulation platform for the validation of autonomous vehicles while using a multi-agent interaction system, it evaluates the perception of the scene, planning algorithms, decision-making, and control of vehicles. Elmquist et al. [108] proposed a framework also related to the validation of autonomous vehicles, the idea is to evaluate the piloting control programs and improve them in a safe environment, one of the main components of this framework is a multi-agent simulated communication support. 


\subsection{Machinery}

For the application considered in the study of Durica et al. [109], a continuous and decentralized route planner is necessary for a modular manufacturing line, therefore they proposed an approach in which a delegate multi-agent system (D-MAS) is used and this approach verified using a simulation with VR.

Xie et al. [110] said that the existing control program for the machines in a mechanized coal mining face doesn't satisfy the dynamic environment of coal mines. Then the authors established a collaborative mathematical model that takes into account the effects of the dynamic environment. They also proposed a collaborative planning simulator in VR with MAS-based methods for the machines.

Wang et al. [111] proposed a Multi-agent based virtual maintenance simulation system (MVMSS) where the virtual human, the tools, and the device can be considered agents. This system would allow a more realistic and natural interaction of the user with the environment.

\subsection{Resolution of Research Questions}

This section will summarize the responses to the research questions posed in Section 2.1.3.

4.9.1. What Applications Have Been Developed with Multi-Agent Systems in the Field of Virtual Reality?

In the Discussion (Section 4), a description of the different applications found while conducting this study was made. These applications are related to different purposes that are described and in which that section has been divided: videogames development [30-39], robot simulation [40,41], interactive virtual environments development [42-45], human behavior simulation [46-99], dissemination of cultural heritage [100,101], urban $m$ development of autonomous vehicles [107,108], and machinery simulation [109-111] (Figure 5).

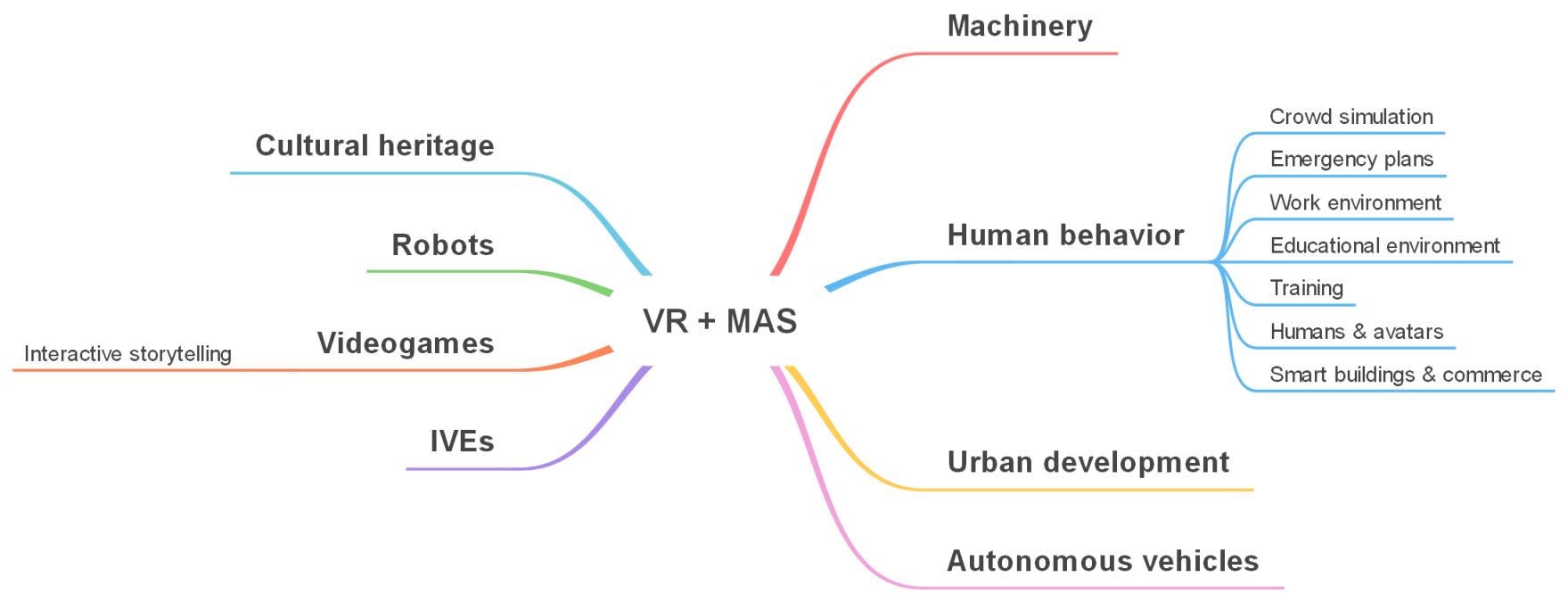

Figure 5. Categorization by purposes of the works.

Also, simulation of human behavior can be divided into subcategories: crowds simulation [57-68], emergency plans [69-72], work environment [73-78], educational environment [79-86], staff training [87-95], interactions between humans and avatars [96,97], and smart buildings and commerce $[98,99]$.

As shown in Figure 6, most of the works found during this study are aimed at simulating human behavior $(65.9 \%)$. This is because it has applications in different areas, as seen in the diagram (Figure 5), and those that have as-purpose crowd simulation, are the ones that represent the majority within the works about human behavior simulation (22.2\%). 


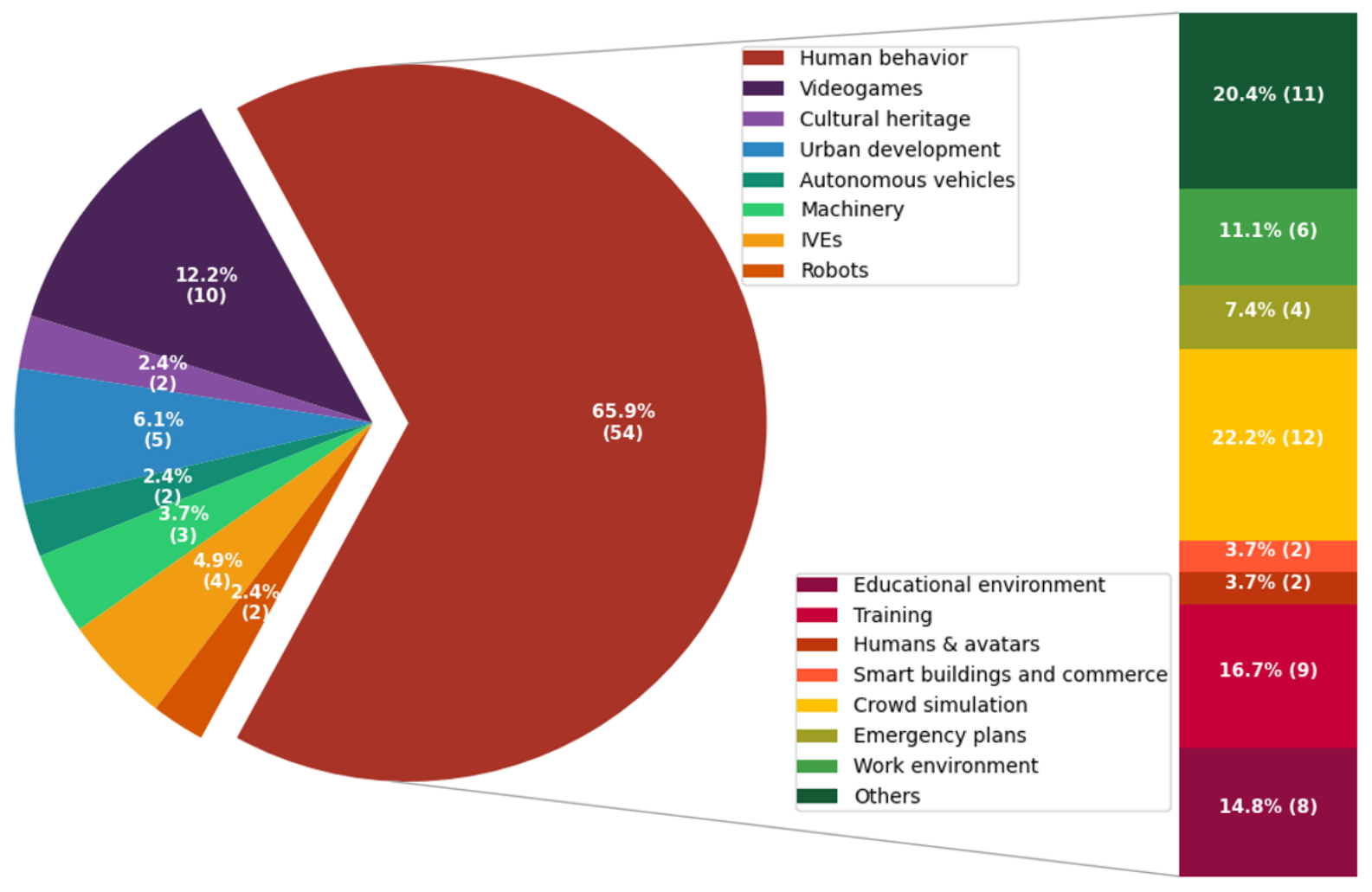

Figure 6. Classification of the works according to the Purpose.

4.9.2. How Does Virtual Reality Benefit from the Use of Multi-Agent Systems?

In general, Virtual Reality applications benefit from Multi-Agent Systems since they allow the development of high-quality applications in a more efficient way. But according to the purpose of the works, Virtual Reality applications benefit in different ways from the use of Multi-Agent Systems, in the case of videogames, MAS serves to improve the user experience, improving the quality of the games [30,32] and creating more realistic stories [31] and characters [33-36]. On the other hand, in the case of robot simulation, the agents are used to make simulations closer to the reality that allows the user to see the movement of the robot when programming them without the need for the physical robot $[40,41]$.

In the case of the development of IVEs, frameworks were presented for their creation in which MAS serve to represent all the objects in the environment [42-45]. In the human behavior simulation, multi-agent systems are used to create different types of movements [46,47] and behaviors [48-56] for avatars and NPCs that are appreciated by the user as realistic so that they can be used for more serious simulations such as emergency plans [69-72], improvements of the labor [73-78] and educational [79-86] environment, personnel training [87-95], etc. For the dissemination of cultural heritage, MAS serve to represent people in the past as well as objects and artifacts $[100,101]$, so that users could learn about it.

Regarding urban development, MAS are used to make realistic simulations of pedestrians, traffic objects, cars, etc., in this way improvements can be made in urban planning [103-106]. In the development of autonomous vehicles, multi-agent systems are used to create an interactive system to validate vehicles in the real world $[107,108]$, in a way that reduces costs and avoids accidents. Likewise, in the simulation of machinery, the MAS are used to simulate the objects that make up the machinery [109-111] in a way that serves as a form of training for the personnel who have to use it. 


\subsection{Future Research}

To talk about future research in this field it is necessary to discuss the research gap. First of all, it can be seen that VR and MAS are technologies with a lot of potentials that, combined, can be very useful in different fields, as has been seen throughout Section 4 .

Now, although in all fields it is possible to find ways to improve what already exists and create new applications, here the importance of the simulation of human behavior is highlighted. This study made it possible to demonstrate the simulation of human behavior is useful in many directly associated fields such as education, training, emergency plans, work environment, etc., but these simulations are also useful in areas in which the main thing is not human behavior such as videogames, dissemination of cultural heritage, urban development, etc.

Many works focus on the relationship between the user and avatars. An important part for the improvement of the user-avatar relationship is the gestural response of the agents, however, this topic has rarely been addressed and less in simulations where there are a large number of agents. There are different studies in which an attempt is made to infer the user's intention, based on that, the agents make a decision. However, these behaviors do not usually also occur between agents, this makes the simulations lose realism since the agents only interact with the user and never between them. Also, this type of inference usually only generates two intentions: avoiding the agent as if it were an obstacle or having face-to-face interaction, a situation that makes simulations unrealistic by not being able to emulate other types of interactions.

Following this line, some studies focus on the changes in the agents' gaze behavior after the inference of the user's intention. However, most of the time this intention has no impact on other aspects of the agent such as changes in their movements or objectives. Likewise, in the real world, gaze behavior is usually accompanied by a change in steering behavior, and this is not usually taken into account in simulations. In the same way, changes in behavior due to events that occur in the environment such as people running or loud noises are rarely taken into account.

On the other hand, when creating human simulations, only the environment is usually taken into account both for decision-making and for the movement of agents, but if what is sought is to make simulations close to reality, it would be necessary to include the mental state of agents (emotions, personality, etc.) as part of the agent's perception process, since these factors influence human attention processes in the real world.

As it is seen, there are quite a few future research lines, here some related to improving the simulation of human behavior were highlighted.

\section{Conclusions}

Advances in both technologies, MAS and VR, have allowed the development of applications of higher quality and realism in different fields. These applications have allowed advances in different areas that are exposed in this paper: videogames development, robot simulation, IVEs development, human behavior simulation, dissemination of cultural heritage, urban development, autonomous vehicles development, and simulation of machinery; either by allowing the simulation of real situations that can become dangerous and expensive to emulate in real life, or allow more realistic simulations and more interesting characters.

To carry out this study, two research questions were established: What applications have been developed with Multi-agent systems in the field of Virtual reality? and How does Virtual Reality benefit from the use of Multi-agent systems? The answers to these questions made it possible to demonstrate the magnitude of research that has been carried out so far in this area.

In the area of development of videogames with virtual reality, multi-agent systems are used mostly to improve the user experience during the game, either by achieving more realistic animations, creating more realistic and complex characters, improving communication between the user and the avatars and characters of the game, among 
others. In the field of robot simulation, the MAS agents serve as representations of the robots, so that collaboration and movement strategies between multiple agents can be simulated. Within the development of intelligent virtual environments, frameworks were proposed that describe the environment for multi-agent systems, environments composed of agents and entities configurable by the user.

It was found that most of the research in this area focuses on the simulation of human behavior, either studying the generation of plausible humans movements for the agents, creating realistic interactions of the human agents with the user, among others. Now, within the simulation of human behavior different fields are addressed: simulation of crowds, simulation of emergency plans, simulation of the work environment, simulation of the educational environment, simulation for the training of personnel, interactions between humans and avatars, and simulation of smart buildings and commerce.

These technologies have also been used to disseminate knowledge about cultural heritage, for this purpose scenarios of the past are usually reconstructed in virtual environments and an interactive environment is created where the user can appreciate all the agents and components of the scenario. Likewise, it can be seen that different research works were carried out in the field of urban development, which in general try through simulations to improve urban planning and then implement it in the real world.

In the development of autonomous vehicles, VR and MAS have also been used, generally to validate, through simulations, the algorithms and other components of these vehicles before putting them into operation in the real world. In the same way, in the field of machinery development, simulations have been created that allow to validate and improve the processes carried out by these machines and can also serve as training for the personnel in charge of putting this machinery into operation.

Performing this study made it possible to demonstrate the magnitude of research that has been carried out on this topic, in addition to highlighting that the majority of research attempts to solve the problem of conducting realistic human behavior simulations, and especially in the simulation of crowds and training staff.

Developments in these areas open the possibility of creating virtual reality applications that use multi-agent systems to train personnel in the field of driving, in an environment in which all objects typical of a city and necessary for training are included as agents, in this way, a realistic environment could be established that serves as a complement to driver training in an environment in which nobody's life is put at risk.

Author Contributions: Conceptualization and methodology A.O.-B., S.R.-G., and D.V.-R.; validation A.O.-B., S.R.-G., and D.V.-R.; formal analysis A.O.-B.; data curation S.R.-G., and D.V.-R.; writingoriginal draft preparation A.O.-B.; writing, review and editing A.O.-B., S.R.-G., and D.V.-R.; All authors have read and agreed to published version of the manuscript.

Funding: This research received no external funding.

Institutional Review Board Statement: Not applicable.

Informed Consent Statement: Not applicable.

Data Availability Statement: Data sharing not applicable.

Acknowledgments: This research has been supported by the project "Intelligent and sustainable mobility supported by multi-agent systems and edge computing (InEDGEMobility): Towards Sustainable Intelligent Mobility: Blockchain-based framework for IoT Security", Reference: RTI2018095390-B-C32, financed by the Spanish Ministry of Science, Innovation and Universities (MCIU), the State Research Agency (AEI) and the European Regional Development Fund (FEDER).

Conflicts of Interest: The authors declare no conflict of interest. 


\section{Abbreviations}

The following abbreviations are used in this manuscript:

$\begin{array}{ll}\text { MAS } & \text { Multi-agent System } \\ \text { VR } & \text { Virtual Reality } \\ \text { SMS } & \text { Systematic Mapping Study } \\ \text { PICO } & \text { Population, Intervention, Comparison, Outcomes } \\ \text { IC1 } & \text { Inclusion Criteria 1 } \\ \text { IC2 } & \text { Inclusion Criteria 2 } \\ \text { IC3 } & \text { Inclusion Criteria 3 } \\ \text { EC1 } & \text { Exclusion Criteria 1 } \\ \text { EC2 } & \text { Exclusion Criteria 2 } \\ \text { EC3 } & \text { Exclusion Criteria 3 } \\ \text { EC4 } & \text { Exclusion Criteria 4 } \\ \text { WoS1 } & \text { Web of Science Search String 1 } \\ \text { WoS2 } & \text { Web of Science Search String 2 } \\ \text { WoS3 } & \text { Web of Science Search String 3 } \\ \text { S1 } & \text { Scopus Search String 1 } \\ \text { S2 } & \text { Scopus Search String 2 } \\ \text { S3 } & \text { Scopus Search String 3 } \\ \text { NPCs } & \text { Non-player Characters } \\ \text { IVEs } & \text { Intelligent Virtual Environments } \\ \text { BAM } & \text { Body Aware Movement } \\ \text { GOAM } & \text { Grid Object and Agent Modeling } \\ \text { EFT } & \text { Emotional Freedom Technique } \\ \text { CFHP } & \text { Crowd Formation framework through Hierarchical Planning } \\ \text { IVP } & \text { Interaction Velocity Prediction } \\ \text { VO } & \text { Virtual Organization } \\ \text { BDI } & \text { Belief, Desire, Intention } \\ \text { ASP } & \text { Answer Set Programming } \\ \text { CRA } & \text { Conflict Resolution Agent } \\ \text { SPA } & \text { Sense-Plan-Ask } \\ \text { BIM } & \text { Building Information Modeling } \\ \text { D-MAS } & \text { Delegate Multi-agent System } \\ \text { MVMSS } & \text { Multi-agent based Virtual Maintenance Simulation System } \\ & \end{array}$




\section{Appendix A}

Table A1. Included papers.

\begin{tabular}{|c|c|c|c|c|c|}
\hline Author & Title & Year & Publication Type & Research Type & Asset Type \\
\hline Ağ1l et al. [61] & $\begin{array}{l}\text { A group-based approach for gaze behavior of virtual } \\
\text { crowds incorporating personalities }\end{array}$ & 2018 & Journal & Conceptual, Experimental & Model, Framework \\
\hline Andelfinger et al. [53] & $\begin{array}{l}\text { Incremental calibration of seat selection preferences in } \\
\text { agent-based simulations of public transport scenarios }\end{array}$ & 2018 & Conference paper & Conceptual, Experimental & Model \\
\hline Antakli et al. [75] & $\begin{array}{l}\text { Intelligent Distributed Human Motion Simulation in } \\
\text { Human-Robot Collaboration Environments }\end{array}$ & 2018 & Conference paper & Conceptual, Experimental & Framework \\
\hline Antakli et al. [76] & $\begin{array}{l}\text { Agent-based web supported simulation of human-robot } \\
\text { collaboration }\end{array}$ & 2019 & Conference paper & Conceptual, Experimental & Framework \\
\hline Antakli et al. [77] & $\begin{array}{l}\text { ASP-Driven BDI-Planning Agents in Virtual 3D Environ- } \\
\text { ments }\end{array}$ & 2016 & Conference paper & Conceptual, Experimental & Architecture, Platform \\
\hline Baierle et al. [80] & $\begin{array}{l}\text { Programming intelligent embodied pedagogical agents to } \\
\text { teach the beginnings of industrial revolution }\end{array}$ & 2018 & Conference paper & $\begin{array}{l}\text { Conceptual, Experimen- } \\
\text { tal, Validation }\end{array}$ & Architecture, Platform \\
\hline Barange et al. [85] & $\begin{array}{l}\text { Pedagogical agents as team members: Impact of proactive } \\
\text { and pedagogical behavior on the user }\end{array}$ & 2017 & Conference paper & $\begin{array}{l}\text { Conceptual, Experimen- } \\
\text { tal, Validation }\end{array}$ & Architecture \\
\hline Barriuso et al. [73] & $\begin{array}{l}\text { MOVICLOUD: Agent-based 3D platform for the labor inte- } \\
\text { gration of disabled people }\end{array}$ & 2018 & Journal & $\begin{array}{l}\text { Conceptual, Experimen- } \\
\text { tal, Validation }\end{array}$ & Framework, Platform \\
\hline Barthes et al. [91] & $\begin{array}{l}\text { Designing Training Virtual Environments Supported by } \\
\text { Cognitive Agents }\end{array}$ & 2018 & Conference paper & Conceptual, Experimental & Architecture, Platform \\
\hline Benkhedda et al. [93] & FASim: A 3D Serious Game for the First Aid Emergency & 2019 & Journal & Conceptual, Experimental & $\begin{array}{l}\text { Architecture, Framework, } \\
\text { Platform }\end{array}$ \\
\hline Bera et al. [54] & $\begin{array}{l}\text { Data-driven modeling of group entitativity in virtual envi- } \\
\text { ronments }\end{array}$ & 2018 & Conference paper & $\begin{array}{l}\text { Conceptual, Experimen- } \\
\text { tal, Validation }\end{array}$ & Method \\
\hline Bera et al. [58] & $\begin{array}{l}\text { Interactive and adaptive data-driven crowd simulation: } \\
\text { User Study }\end{array}$ & 2016 & Conference paper & Experimental, Validation & $\mathrm{N} / \mathrm{A}$ \\
\hline Best et al. [96] & $\begin{array}{l}\text { SPA: Verbal Interactions between Agents and Avatars in } \\
\text { Shared Virtual Environments using Propositional Planning }\end{array}$ & 2020 & Conference paper & $\begin{array}{l}\text { Conceptual, Experimen- } \\
\text { tal, Validation }\end{array}$ & $\mathrm{N} / \mathrm{A}$ \\
\hline Blankendaal et al. [87] & $\begin{array}{l}\text { Using run-time biofeedback during virtual agent-based } \\
\text { aggression de-escalation training }\end{array}$ & 2018 & Conference paper & $\begin{array}{l}\text { Conceptual, Experimen- } \\
\text { tal, Validation }\end{array}$ & Platform \\
\hline
\end{tabular}


Table A1. Cont.

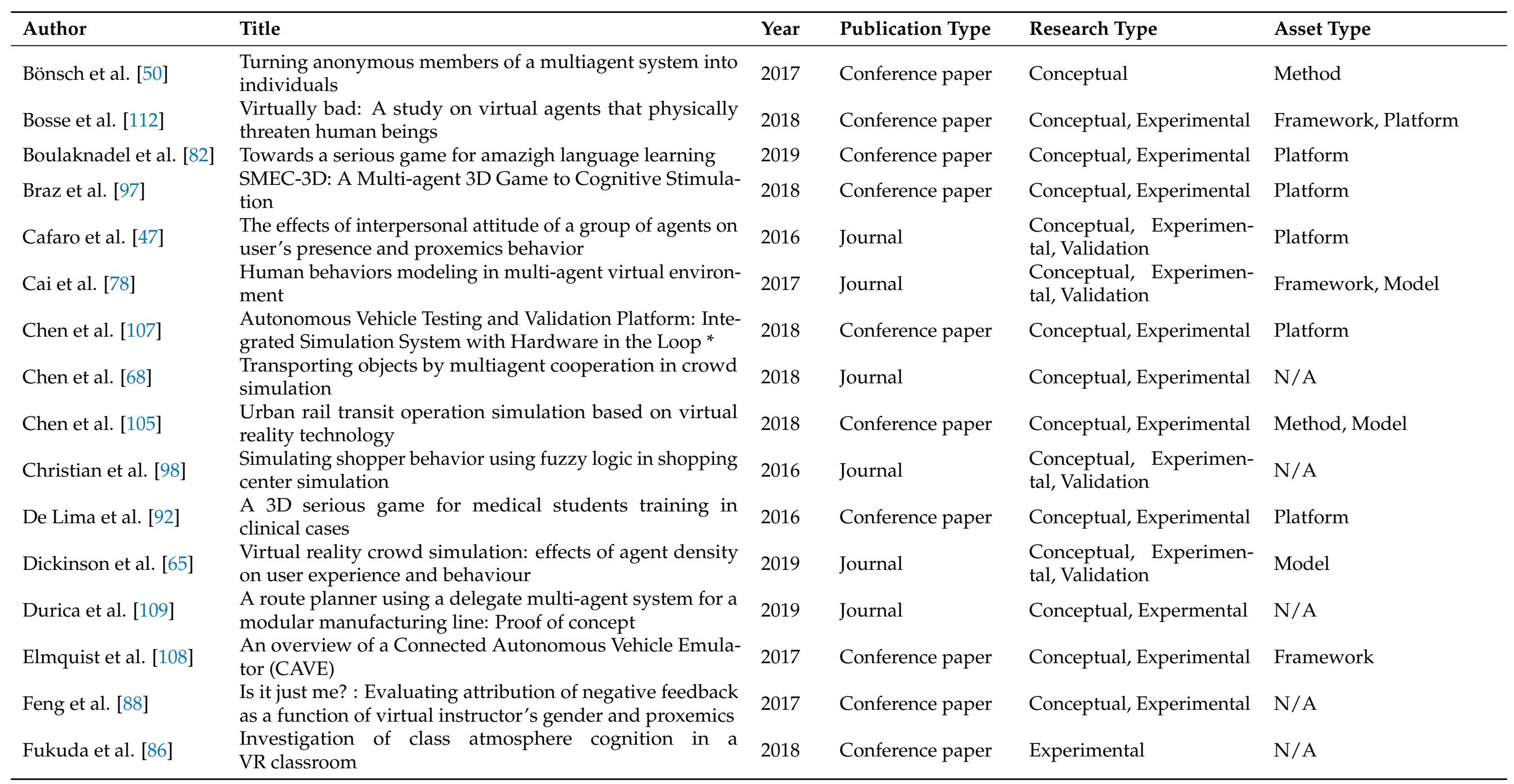


Table A1. Cont.

\begin{tabular}{|c|c|c|c|c|c|}
\hline Author & Title & Year & Publication Type & Research Type & Asset Type \\
\hline García-Ortega et al. [31] & $\begin{array}{l}\text { The Story of Their Lives: Massive Procedural Generation } \\
\text { of Heroes' Journeys Using Evolved Agent-Based Models } \\
\text { and Logical Reasoning }\end{array}$ & 2016 & Conference paper & Conceptual, Experimental & Methodology \\
\hline Garg et al. [106] & Traffic3D: A new traffic simulation paradigm & 2019 & Conference paper & Conceptual, Experimental & Platform \\
\hline Jayalath et al. [67] & $\begin{array}{l}\text { Modelling goal selection of characters in primary groups } \\
\text { in crowd simulations }\end{array}$ & 2016 & Journal & Conceptual, Experimental & Model \\
\hline Johnson et al. [89] & $\begin{array}{l}\text { Towards an autonomous agent that provides automated } \\
\text { feedback on students' negotiation skills }\end{array}$ & 2017 & Conference paper & Conceptual, Experimental & $\mathrm{N} / \mathrm{A}$ \\
\hline Kim et al. [57] & Interactive and adaptive data-driven crowd simulation & 2016 & Conference paper & Conceptual, Experimental & $\mathrm{N} / \mathrm{A}$ \\
\hline Kiourt et al. [101] & $\begin{array}{l}\text { Multi-agents based virtual environments for cultural her- } \\
\text { itage }\end{array}$ & 2017 & Conference paper & Conceptual, Experimental & Framework \\
\hline Lakshika et al. [30] & $\begin{array}{l}\text { Understanding the Interplay of Model Complex- } \\
\text { ity and Fidelity in Multiagent Systems via an } \\
\text { Evolutionary Framework }\end{array}$ & 2017 & Journal & Conceptual, Experimental & Framework \\
\hline Li et al. [69] & $\begin{array}{l}\text { Flood evacuation simulations using cellular automata and } \\
\text { multiagent systems -a human-environment relationship } \\
\text { perspective }\end{array}$ & 2019 & Journal & $\begin{array}{l}\text { Conceptual, Experimen- } \\
\text { tal, Validation }\end{array}$ & Model \\
\hline Makarov et al. [33] & $\begin{array}{l}\text { First-Person Shooter Game for Virtual Reality Headset with } \\
\text { Advanced Multi-Agent Intelligent System }\end{array}$ & 2016 & Conference paper & $\begin{array}{l}\text { Conceptual, Experimen- } \\
\text { tal, Validation }\end{array}$ & $\mathrm{N} / \mathrm{A}$ \\
\hline Mao et al. [71] & $\begin{array}{l}\text { Personality trait and group emotion contagion based crowd } \\
\text { simulation for emergency evacuation }\end{array}$ & 2020 & Journal & Conceptual, Experimental & Framework \\
\hline Matthews et al. [38] & Mise-en-scène of narrative action in interactive storytelling & 2017 & Conference paper & Experimental & Framework \\
\hline Matthews et al. [37] & $\begin{array}{l}\text { MISER: Mise-En-Scène region support for staging narrative } \\
\text { actions in interactive storytelling }\end{array}$ & 2017 & Conference paper & $\begin{array}{l}\text { Conceptual, Experimen- } \\
\text { tal, Validation }\end{array}$ & Framework \\
\hline Montana et al. [66] & $\begin{array}{l}\text { A Sketch-based Interface for Real-time Control of Crowd } \\
\text { Simulations that Use Navigation Meshes }\end{array}$ & 2019 & Conference paper & $\begin{array}{l}\text { Conceptual, Experimen- } \\
\text { tal, Validation }\end{array}$ & $\mathrm{N} / \mathrm{A}$ \\
\hline Montecchiari et al. [72] & $\begin{array}{l}\text { Towards real-time human participation in virtual evacua- } \\
\text { tion through a validated simulation tool }\end{array}$ & 2018 & Journal & Conceptual, Experimental & Model \\
\hline Narang et al. [62] & $\begin{array}{l}\text { PedVR: Simulating gaze-based interactions between a real } \\
\text { user and virtual crowds }\end{array}$ & 2016 & Conference paper & $\begin{array}{l}\text { Conceptual, Experimen- } \\
\text { tal, Validation }\end{array}$ & $\mathrm{N} / \mathrm{A}$ \\
\hline Narang et al. [46] & $\begin{array}{l}\text { Simulating Movement Interactions between Avatars Agents } \\
\text { in Virtual Worlds Using Human Motion Constraints }\end{array}$ & 2018 & Conference paper & Conceptual, Experimental & $\mathrm{N} / \mathrm{A}$ \\
\hline
\end{tabular}


Table A1. Cont.




Table A1. Cont.

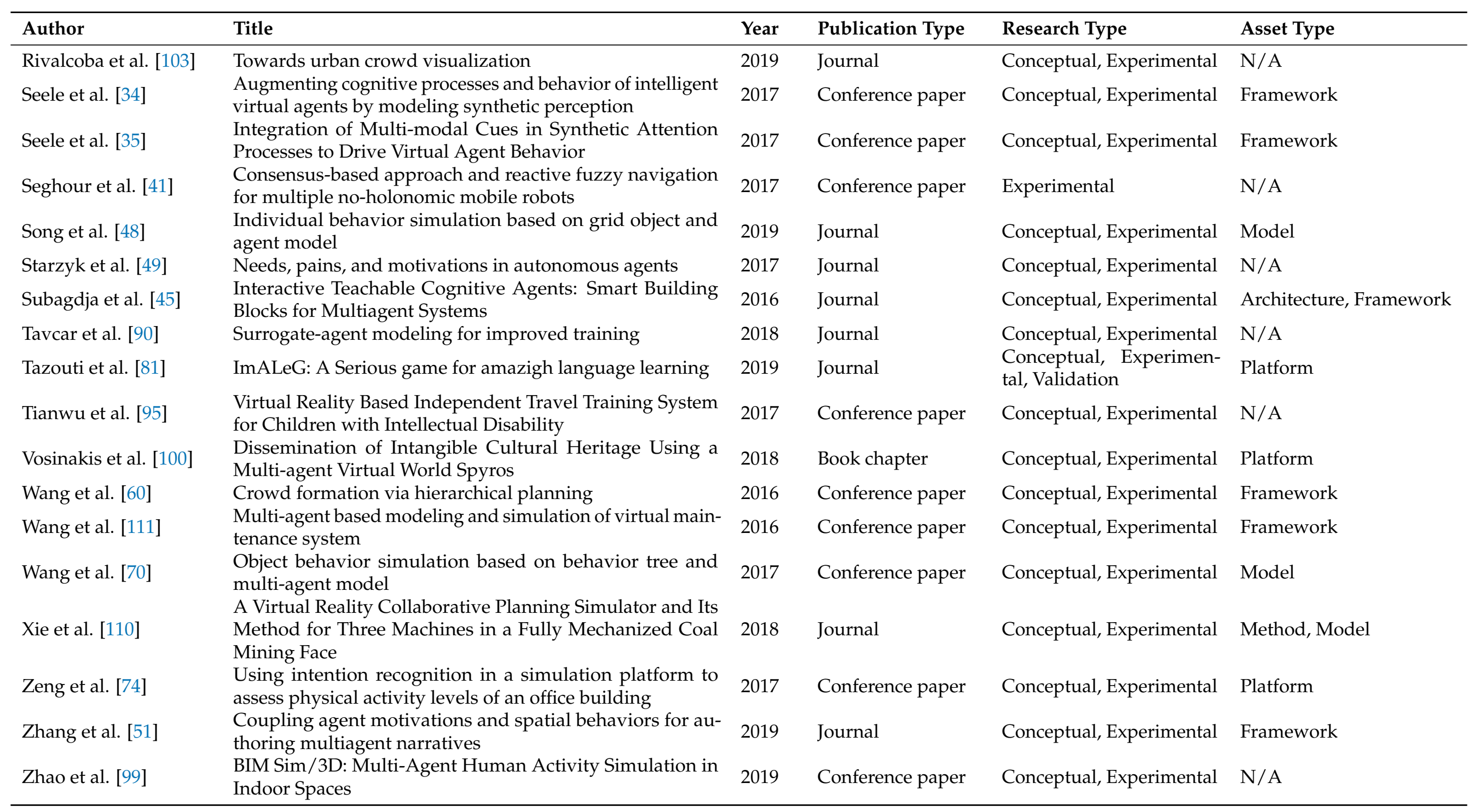




\section{References}

1. Oprea, M. Applications of multi-agenty systems. In Proceedings of the Information Technology. IFIP 18th World Computer Congress, Toulouse, France, 22-27 August 2004; Reis, R., Ed.; Springer: Boston, MA, USA, 2004; pp. $239-270$.

2. De Paz, J.F.; Bajo, J.; Rodríguez, S.; Villarrubia, G.; Corchado, J.M. Intelligent system for lighting control in smart cities. Inf. Sci. 2016, 372, 241-255. [CrossRef]

3. Rodríguez, S.; De Paz, Y.; Bajo, J.; Corchado, J.M. Social-based planning model for multiagent systems. Expert Syst. Appl. 2011, 38, 13005-13023. [CrossRef]

4. Corchado, J.M.; Laza, R. Constructing deliberative agents with case-based reasoning technology. Int. J. Intell. Syst. 2003, 18, 1227-1241. [CrossRef]

5. Corchado, J.M.; Bajo, J.; Tapia, D.I.; Abraham, A. Using Heterogeneous Wireless Sensor Networks in a Telemonitoring System for Healthcare. IEEE Trans. Inf. Technol. Biomed. 2010, 14, 234-240. [CrossRef] [PubMed]

6. Grieu, J.; Lecroq, F.; Boukachour, H.; Galinho, T. Industrial Virtual Environments and Learning Process. In Proceedings of the Online Engineering and Internet of Things, 14th International Conference on Remote Engineering and Virtual Instrumentation (REV), Columbia University, New York, NY, USA, 15-17 March 2017; Auer, M.; Zutin, D., Eds.; Springer: Cham, Switzerland, 2018; pp. 609-618.

7. Balaji, P.G.; Srinivasan, D. An Introduction to Multi-Agent Systems. In Innovations in Multi-Agent Systems and Applications-1. Studies in Computational Intelligence; Srinivasan, D., Jain, L.C., Eds.; Springer: Berlin/Heidelberg, Germany, 2010; Volume 310, pp. 1-27.

8. Vergara, D.; Rubio, M.P.; Lorenzo, M. On the Design of Virtual Reality Learning Environments in Engineering. Multimodal Technol. Interact. 2017, 1, 11. [CrossRef]

9. Vergara, D.; Extremera, J.; Rubio, M.P.; Dávila, L.P. The proliferation of virtual laboratories in educational fields. Adv. Distrib. Comput. Artif. Intell. J. 2020, 9, 85-97.

10. Extremera, J.; Vergara, D.; Dávila, L.P.; Rubio, M.P. Virtual and Augmented Reality Environments to Learn the Fundamentals of Crystallography. Crystals 2020, 10, 456. [CrossRef]

11. Ospina, A. Diseño de una Aplicación de Realidad Virtual Inmersiva de Simulación de Accidentes y su Conexión con un Sistema mecánico Real. Bachelor's Thesis, University of Salamanca, Zamora, Spain, June 2018.

12. Erkan, I. Investigation of the contribution of virtual reality to architectural education. Art Des. Commun. High. Educ. 2020, 19, 221-240. [CrossRef]

13. Abdelhameed, W.A. Virtual Reality Use in Architectural Design Studios: A case of studying structure and construction. In Proceedings of the Procedia Computer Science, VARE 2013: International Conference on Virtual and Augmented Reality in Education, Puerto de la Cruz, Spain, 7-8 November 2013; Martin-Guitierrez, J., Ginter, E., Eds. Elsevier: Amsterdam, The Netherlands, 2013; pp. 220-230.

14. Singh, A.; Ferry, D.; Ramakrishnan, A.; Balasubramanian, S. Using Virtual Reality in Biomedical Engineering Education. J. Biomech. Eng. Trans. ASME 2020, 142, 11. [CrossRef]

15. Agasthya, N.; Penfil, S.; Slamon, N. Virtual Reality Simulation for Pediatric Airway Intubation Readiness Education. Cureus J. Med. Sci. 2020, 12, e12059.

16. Grabowski, A.; Jach, K. The use of virtual reality in the training of professionals: with the example of firefighters. Comput. Animat. Virtual Worlds 2020, 1-6.

17. Guttentag, D.A. Virtual reality: Applications and implications for tourism. Tour. Manag. 2010, 31, 637-651. [CrossRef]

18. Schnack, A.; Wright, M.J.; Holdershaw, J.L. An exploratory investigation of shopper behaviour in an immersive virtual reality store. J. Consumer Behav. 2019, 19, 182-195. [CrossRef]

19. Pérez-Ramírez, M.; Zayas, B.; Rodrigo, B.; Márquez, D.; Ochoa-Zezzatti, C. Implementation of a Reactive Model for Responding to a Trembling Earthquake: A Perspective from Virtual Reality and Multiagent Systems. Res. Comput. Sci. 2018, 122, 25-35. [CrossRef]

20. Vergara, D.; Rubio, M.P. The application of didactic virtual tools in the instruction of industrial radiography. J. Mater. Educ. 2015, 37, 17-26.

21. Granic, I.; Lobel, A.; Engels, R.C. The benefits of playing video games. Am. Psychol. 2014, 69, 66-78. [CrossRef]

22. Simonov, A.; Lebin, A.; Shcherbak, B.; Zagarskikh, A.; Karsakov, A. Multi-agent crowd simulation on large areas with utility-based behavior models: Sochi Olympic Park Station use case. Procedia Comput. Sci. 2018, 136, 453-462. [CrossRef]

23. Rodríguez, S.; De La Prieta, F.; Tapia, D.; Corchado Rodríguez, J. Agents and Computer Vision for Processing Stereoscopic Images. In Proceedings of the Hybrid Artificial Intelligence Systems, 5th International Conference, HAIS 2010, San Sebastián, Spain, 23-25 June 2010; Corchado, E., Graña Romay, M., Manhaes Savio, A., Eds.; Springer: Berlin/ Heidelberg, Germany, 2010 ; pp. 93-100.

24. Kitchenham, B.; Budgen, D.; Brereton, P. Using mapping studies as the basis for further research-A participant-observer case study. Inf. Softw. Technol. 2011, 53, 638-651. [CrossRef]

25. Petersen, K.; Vakkalanka, S.; Kuzniarz, L. Guidelines for conducting systematic mapping studies in software engineering: An update. Inf. Softw. Technol. 2015, 64, 1-18. [CrossRef]

26. Odun-Ayo, I.; Goddy-Worlu, R.; Geteloma, V.; Grant, E. A Systematic Mapping Study of Cloud, Fog, and Edge/Mobile Devices Management, Hierarchy Models and Business Models. Adv. Sci. Technol. Eng. Syst. J. 2019, 4, 91-101. [CrossRef] 
27. Sittón-Candanedo, I.; Alonso, R.; García, Ó.; Gil, A.; Rodríguez, S. A Review on Edge Computing in Smart Energy by means of a Systematic Mapping Study. Electronics 2020, 9, 48. [CrossRef]

28. Kitchenham, B.; Charters, S. Guidelines for performing Systematic Literature Reviews in Software Engineering. In Keele University and Durham University Joint Report; EBSE Technical Report EBSE-2007-01; Software Engineering Group, School of Computer Science and Mathematics, Keele University and Department of Computer Science University of Durham: Durham, UK, 2007.

29. Petersen, K.; Feldt, R.; Mujtaba, S.; Mattsson, M. Systematic Mapping Studies in Software Engineering. In Proceedings of the 12th International Conference on Evaluation and Assessment in Software Engineering (EASE'08), Bari, Italy, 26-27 June 2008; Visaggio, G., Baldassarre, M.T., Linkman, S., Eds.; BCS Learning \& Development Ltd.: Swindon, UK, 2008; pp. 68-77.

30. Lakshika, E.; Barlow, M.; Easton, A. Understanding the Interplay of Model Complexity and Fidelity in Multi-agent Systems via an Evolutionary Framework. IEEE Trans. Comput. Intell. AI Games 2017, 9, 277-289. [CrossRef]

31. García-Ortega, R.; García-Sánchez, P.; Merelo Guervós, J.; San-Ginés, A.; Fernández-Cabezas, A. The Story of Their Lives: Massive Procedural Generation of Heroes' Journeys Using Evolved Agent-Based Models and Logical Reasoning. In Proceedings of the Applications of Evolutionary Computation, 19th European Conference, EvoApplications 2016, Porto, Portugal, 30 March-1 April 2016; Giovanni, S., Paolo, B., Eds.; Springer: Cham, Switzerland, 2016; pp. 604-619.

32. Narang, S.; Best, A.; Manocha, D. Inferring User Intent using Bayesian Theory of Mind in Shared Avatar-Agent Virtual Environments. IEEE Trans. Vis. Comput. Graphics 2019, 25, 2113-2122. [CrossRef]

33. Makarov, I.; Tokmakov, M.; Poluakov, P. First-Person Shooter Game for Virtual Reality Headset with Advanced Multi-Agent Intelligent System. In Proceedings of the 24th ACM International Conference on Multimedia, Amsterdam, The Netherlands, 15-19 October 2016; Association for Computing Machinery: New York, NY, USA, 2016; pp. 735-736.

34. Seele, S.; Haubrich, T.; Schild, J.; Herpers, R.; Grzegorzek, M. Augmenting Cognitive Processes and Behavior of Intelligent Virtual Agents by Modeling Synthetic Perception. In Proceedings of the on Thematic Workshops of ACM Multimedia, Mountain View, CA, USA, 23-27 October 2017; Association for Computing Machinery: New York, NY, USA, 2017; pp. 117-125.

35. Seele, S.; Haubrich, T.; Schild, J.; Herpers, R.; Grzegorzek, M. Integration of Multi-modal Cues in Synthetic Attention Processes to Drive Virtual Agent Behavior. In Proceedings of the Intelligent Virtual Agents, 17th International Conference, IVA 2017, Stockholm, Sweden, 27-30 August 2017; Beskow, J., Peters, C., Castellano, G., O'Sullivan, C., Leite, I., Kopp, S., Eds.; Springer: Cham, Switzerland, 2017; pp. 403-412.

36. Nunnari, F.; Héloir, A. Yet another low-level agent handler. Comput. Animat. Virtual Worlds 2019, 30, e1891. [CrossRef]

37. Matthews, J.; Charles, F.; Porteous, J.; Mendes, A. MISER: Mise-En-ScèNe Region Support for Staging Narrative Actions in Interactive Storytelling. In Proceedings of the 16th Conference on Autonomous Agents and MultiAgent Systems, São Paulo, Brazil, 8-12 May 2017; International Foundation for Autonomous Agents and Multiagent Systems: Richland, SC, USA, 2017; pp. 782-790.

38. Matthews, J.; Charles, F.; Porteous, J.; Mendes, A. Mise-En-ScèNe of Narrative Action in Interactive Storytelling. In Proceedings of the 16th Conference on Autonomous Agents and MultiAgent Systems, São Paulo, Brazil, 8-12 May 2017; International Foundation for Autonomous Agents and Multiagent Systems: Richland, SC, USA, 2017; pp. 1799-1801.

39. Porteous, J.; Charles, F.; Smith, C.; Cavazza, M.; Mouw, J.; van den Broek, P. Using Virtual Narratives to Explore Children's Story Understanding. In Proceedings of the AAMAS '17: 16th Conference on Autonomous Agents and MultiAgent Systems, São Paulo, Brazil, 8-12 May 2017; International Foundation for Autonomous Agents and Multiagent Systems: Richland, SC, USA, 2019; pp. 773-781.

40. Raza, S.; Haider, S. Using Imitation to Build Collaborative Agents. ACM Trans. Auton. Adapt. Syst. 2016, 11, 3. [CrossRef]

41. Seghour, S.; Tadjine, M. Consensus-based approach and reactive fuzzy navigation for multiple no-holonomic mobile robots. In Proceedings of the 2017 6th International Conference on Systems and Control (ICSC), Batna, Algeria, 7-9 May 2017; Drid, S., Mehdi, D., Aitouche, A., Eds.; IEEE: New York, NY, USA, 2017; pp. 492-497.

42. Rincón, J.A.; García, E.; Julian, V.; Carrascosa, C. The JaCalIVE framework for MAS in IVE: A case study in evolving modular robotics. Neurocomputing 2018, 275, 608-617. [CrossRef]

43. Rincón, J.A.; Botti, V.; Julian, V. Extending JaCallVE framework to create virtual worlds by means of an OWL ontology. In Proceedings of the AAMAS'17: 2017 International Conference on Autonomous Agents \& Multiagent Systems, São Paulo, Brazil, 8-12 May 2017; International Foundation for Autonomous Agents and Multiagent Systems: Richland, SC, USA, 2017; pp. 1714-1715.

44. Okreša Đurić, B.; Rincon, J.; Carrascosa, C.; Schatten, M.; Julian, V. MAMbO5: A new ontology approach for modelling and managing intelligent virtual environments based on multi-agent systems. J. Ambient Intell. Humaniz. Comput. 2018, 10, 3629-3641. [CrossRef]

45. Subagdja, B.; Tan, A.H. Interactive Teachable Cognitive Agents: Smart Building Blocks for Multiagent Systems. IEEE Trans. Syst. Man Cybern. Syst. 2016, 46, 1724-1735. [CrossRef]

46. Narang, S.; Best, A.; Manocha, D. Simulating Movement Interactions Between Avatars \& Agents in Virtual Worlds Using Human Motion Constraints. In Proceedings of the 2018 IEEE Conference on Virtual Reality and 3D User Interfaces (VR), Reutlingen, Germany, 18-22 March 2018; IEEE: New York, NY, USA, 2018; pp. 9-16.

47. Cafaro, A.; Ravenet, B.; Ochs, M.; Vilhjálmsson, H.H.; Pelachaud, C. The Effects of Interpersonal Attitude of a Group of Agents on User's Presence and Proxemics Behavior. ACM Trans. Interact. Intell. Syst. 2016, 6, 12. [CrossRef] 
48. Song, Y.; Niu, L.; Li, Y. Individual Behavior Simulation Based on Grid Object and Agent Model. ISPRS Int. J. Geo-Inf. 2019, 8, 388. [CrossRef]

49. Starzyk, J.A.; Graham, J.; Puzio, L. Needs, Pains, and Motivations in Autonomous Agents. IEEE Trans. Neural Netw. Learn. Syst. 2017, 28, 2528-2540. [CrossRef]

50. Bönsch, A.; Vierjahn, T.; Shapiro, A.; Kuhlen, T. Turning anonymous members of a multiagent system into individuals. In Proceedings of the IEEE Virtual Humans and Crowds for Immersive Environments (VHCIE), Los Angeles, CA, USA, 19 March 2017; IEEE: New York, NY, USA, 2017; pp. 1-4.

51. Zhang, X.; Schaumann, D.; Haworth, B.; Faloutsos, P.; Kapadia, M. Coupling agent motivations and spatial behaviors for authoring multiagent narratives. Comput. Animat. Virtual Worlds 2019, 30, e1898. [CrossRef]

52. Puig, X.; Ra, K.; Boben, M.; Li, J.; Wang, T.; Fidler, S.; Torralba, A. VirtualHome: Simulating Household Activities Via Programs. In Proceedings of the IEEE/CVF Conference on Computer Vision and Pattern Recognition, Salt Lake City, UT, USA, 18-23 June 2018; IEEE: New York, NY, USA, 2018; pp. 8494-8502.

53. Andelfinger, P.; Chen, Y.; Su, B.; Cai, W.; Zehe, D.; Eckhoff, D.; Knoll, A. Incremental calibration of seat selection preferences in agent-based simulations of public transport scenarios. In Proceedings of the Winter Simulation Conference (WSC), Gothenburg, Sweden, 9-12 December 2018; IEEE: New York, NY, USA, 2018; pp. 833-844.

54. Bera, A.; Randhavane, T.; Kubin, E.; Shaik, H.; Gray, K.; Manocha, D. Data-Driven Modeling of Group Entitativity in Virtual Environments. In Proceedings of the VRST '18: 24th ACM Symposium on Virtual Reality Software and Technology, Tokyo, Japan, 28 November-1 December 2018; Association for Computing Machinery: New York, NY, USA, 2018; pp. 1-10.

55. Ranjbartabar, H.; Richards, D. A Virtual Emotional Freedom Therapy Practitioner: (Demonstration). In Proceedings of the AAMAS '16: 2016 International Conference on Autonomous Agents \& Multiagent Systems, Singapore, 9-10 May 2016; International Foundation for Autonomous Agents and Multiagent Systems: Richland, SC, USA, 2016; pp. 1471-1473.

56. Ohmoto, Y.; Marimoto, T.; Nishida, T. Effects of the Perspectives that Influenced on the Human Mental Stance in the Multiple-toMultiple Human-Agent Interaction. Procedia Comput. Sci. 2017, 112, 1506-1515. [CrossRef]

57. Kim, S.; Bera, A.; Best, A.; Chabra, R.; Manocha, D. Interactive and adaptive data-driven crowd simulation. In Proceedings of the 2016 IEEE Virtual Reality (VR), Greenville, SC, USA, 19-23 March 2016; Höllerer, T., Interrante, V., Lécuyer, A., Suma, E., Eds.; IEEE: New York, NY, USA, 2016; pp. 29-38.

58. Bera, A.; Kim, S.; Manocha, D. Interactive and adaptive data-driven crowd simulation: User study. In Proceedings of the 2016 IEEE Virtual Reality (VR), Greenville, SC, USA, 19-23 March 2016; Höllerer, T., Interrante, V., Lécuyer, A., Suma, E., Eds.; IEEE: New York, NY, USA, 2016; p. 325.

59. Phon-Amnuaisuk, S.; Rafi, A.; Au, T.W.; Omar, S.; Voon, N.H. Crowd Simulation in 3D Virtual Environments. In Proceedings of the Multi-disciplinary Trends in Artificial Intelligence, 10th International Workshop, MIWAI 2016, Chiang Mai, Thailand, 7-9 December 2016; Sombattheera, C., Stolzenburg, F., Lin, F., Nayak, A., Eds.; Springer: Cham, Switzerland, 2016 ; pp. $162-172$.

60. Wang, X.; Liu, N.; Liu, S.; Wu, Z.; Zhou, M.; He, J.; Cheng, P.; Miao, C.; Thalmann, N.M. Crowd Formation via Hierarchical Planning. In Proceedings of the VRCAI '16: 15th ACM SIGGRAPH Conference on Virtual-Reality Continuum and Its Applications in Industry, Zhuhai, China, 3-4 December 2016; Association for Computing Machinery: New York, NY, USA, 2016.

61. Ağıl, U.; Güdükbay, U. A group-based approach for gaze behavior of virtual crowds incorporating personalities. Comput. Animat. Virtual Worlds 2018, 29, e1806. [CrossRef]

62. Narang, S.; Best, A.; Randhavane, T.; Shapiro, A.; Manocha, D. PedVR: Simulating Gaze-Based Interactions between a Real User and Virtual Crowds. In Proceedings of the VRST '16: 22nd ACM Conference on Virtual Reality Software and Technology, Munich, Germany, 2-4 November 2016; Association for Computing Machinery: New York, NY, USA, 2016; pp. 91-100.

63. Novick, D.; Hinojos, L.J.; Rodriguez, A.E.; Camacho, A.; Afravi, M. The Market Scene: Physical Interaction with Multiple Agents. In Proceedings of the HAI '18: 6th International Conference on Human-Agent Interaction, Southampton, UK, 15-18 December 2018; Association for Computing Machinery: New York, NY, USA, 2018; pp. 387-388.

64. Randhavane, T.; Bera, A.; Manocha, D. F2Fcrowds: Planning Agent Movements to Enable Face-to-Face Interactions. Presence Teleoperators Virtual Environ. 2017, 26, 228-246. [CrossRef]

65. Dickinson, P.; Gerling, K.; Hicks, K.; Murray, J.; Shearer, J.; Greenwood, J. Virtual reality crowd simulation: Effects of agent density on user experience and behaviour. Virtual Real. 2019, 23, 19-32. [CrossRef]

66. Montana, L.; Maddock, S. A Sketch-based Interface for Real-time Control of Crowd Simulations that Use Navigation Meshes. In Proceedings of the 14th International Joint Conference on Computer Vision, Imaging and Computer Graphics Theory and Applications, Prague, Czech Republic, 25-27 February 2019; Cláudio, A.P., Bouatouch, K., Braz, J., Eds.; SciTePress: Setúbal, Portugal, 2018; pp. 41-52.

67. Jayalath, C.; Wimalaratne, P.; Karunananda, A. Modelling Goal Selection of Characters in Primary Groups in Crowd Simulations. Int. J. Simul. Modell. 2016, 15, 585-596. [CrossRef]

68. Chen, H.; Wong, S.K. Transporting objects by multiagent cooperation in crowd simulation: Transporting Objects by Multi-Agent Cooperation. Comput. Animat. Virtual Worlds 2018, 29, e1826. [CrossRef]

69. Li, Y.; Hu, B.; Zhang, D.; Gong, J.; Song, Y.; Sun, J. Flood evacuation simulations using cellular automata and multiagent systems -a human-environment relationship perspective. Int. J. Geogr. Inf. Sci. 2019, 33, 2241-2258. [CrossRef] 
70. Wang, Y.; Wang, L.; Liu, J. Object behavior simulation based on behavior tree and multi-agent model. In Proceedings of the 2017 IEEE 2nd Information Technology, Networking, Electronic and Automation Control Conference (ITNEC), Chengdu, China, 12-15 December 2017; IEEE: New York, NY, USA, 2017; pp. 833-836.

71. Mao, Y.; Yang, S.; Li, Z. Personality trait and group emotion contagion based crowd simulation for emergency evacuation. Multimed. Tools Appl. 2020, 79, 3077-3104. [CrossRef]

72. Montecchiari, G.; Bulian, G.; Gallina, P. Towards real-time human participation in virtual evacuation through a validated simulation tool. J. Risk Reliab. 2018, 232, 476-490. [CrossRef]

73. Barriuso, A.; De La Prieta, F.; Villarrubia, G.; Hernández de la Iglesia, D.; Lozano Murciego, Á. MOVICLOUD: Agent-based 3D platform for the labor integration of disabled people. Appl. Sci. 2018, 8, 337. [CrossRef]

74. Zeng, Y.; Zhang, Z.; Han, T.A.; Spears, I.R.; Qin, S. Using Intention Recognition in a Simulation Platform to Assess Physical Activity Levels of an Office Building. In Proceedings of the AAMAS '17: Proceedings of the 16th Conference on Autonomous Agents and MultiAgent Systems, São Paulo, Brazil, 8-12 May 2017; International Foundation for Autonomous Agents and Multiagent Systems: Richland, SC, USA, 2017; pp. 1817-1819.

75. Antakli, A.; Hermann, E.; Zinnikus, I.; Du, H.; Fischer, K. Intelligent Distributed Human Motion Simulation in Human-Robot Collaboration Environments. In Proceedings of the IVA '18: Proceedings of the 18th International Conference on Intelligent Virtual Agents, Sydney, NSW, Australia, 2-5 July 2019; Association for Computing Machinery: New York, NY, USA, 2018; pp. 319-324.

76. Antakli, A.; Spieldenner, T.; Rubinstein, D.; Spieldenner, D.; Herrmann, E.; Sprenger, J.; Zinnikus, I. Agent-based Web Supported Simulation of Human-robot Collaboration. In Proceedings of the 15th International Conference on Web Information Systems and Technologies, Vienna, Austria, 18-20 September 2019; Bozzon, A., Domínguez Mayo, F., Filipe, J., Eds.; SciTePress: Setúbal, Portugal, 2019; pp. 88-99.

77. Antakli, A.; Zinnikus, I.; Klusch, M. ASP-Driven BDI-Planning Agents in Virtual 3D Environments. In Proceedings of the Multiagent System Technologies, 14th German Conference, MATES 2016, Klagenfurt, Österreich, Austria, 27-30 September 2016; Klusch, M., Unland, R., Shehory, O., Pokahr, A., Ahrndt, S., Eds.; Springer: Cham, Switzerland, 2016; pp. 198-214.

78. Cai, L.; Liu, B.; Yu, J.; Zhang, J. Human Behaviors Modeling in Multi-Agent Virtual Environment. Multimed. Tools Appl. 2017, 76, 5851-5871. [CrossRef]

79. Calvo, O.; Molina, J.; Patricio, M.A.; Berlanga, A. A Propose Architecture for Situated Multi-agent Systems and Virtual Simulated Environments Applied to Educational Immersive Experiences. In Proceedings of the Biomedical Applications Based on Natural and Artificial Computing, International Work-Conference on the Interplay Between Natural and Artificial Computation, IWINAC, Corunna, Spain, 19-23 June 2017; Ferrández Vicente, J.M., Álvarez Sánchez, J.R., De La Paz López, F., Toledo Moreo, J., Adeli, H., Eds.; Springer: Cham, Switzerland, 2017; pp. 413-423.

80. Baierle, I.L.F.; Gluz, J.C. Programming Intelligent Embodied Pedagogical Agents to Teach the Beginnings of Industrial Revolution. In Proceedings of the Intelligent Tutoring Systems, ITS 2018: International Conference on Intelligent Tutoring Systems, Montreal, QC, Canada, 11-15 June 2018; Nkambou, R., Azevedo, R., Vassileva, J., Eds.; Springer: Cham, Switzerland, 2018 ; pp. 3-12.

81. Tazouti, Y.; Boulaknadel, S.; Fakhri, Y. ImALeG: A Serious Game for Amazigh Language Learning. Int. J. Emerg. Technol. Learn. (iJET) 2019, 14, 28-38. [CrossRef]

82. Boulaknadel, S.; Tazouti, Y.; Fakhri, Y. Towards a Serious Game for Amazigh Language Learning. In Proceedings of the 2019 IEEE/ACS 16th International Conference on Computer Systems and Applications (AICCSA), Abu Dhabi, United Arab Emirates, 3-7 November 2019; IEEE: New York, NY, USA, 2019; pp. 1-5.

83. Nilsson, J.; Klügl, F. Human-in-the-Loop Simulation of a Virtual Classroom. In Proceedings of the Multi-Agent Systems and Agreement Technologies, 13th European Conference on Multi-Agent Systems (EUMAS), Athens, Greece, 17-18 December 2015; Rovatsos, M., Vouros, G., Julian, V., Eds.; Springer: Cham, Switzerland, 2016; pp. 379-394.

84. Lugrin, J.L.; Charles, F.; Habel, M.; Matthews, J.; Dudaczy, H.; Oberdörfer, S.; Wittmann, A.; Seufert, C.; Porteous, J.; Grafe, S.; et al. Benchmark Framework for Virtual Students' Behaviours. In Proceedings of the AAMAS '18: Proceedings of the 17th International Conference on Autonomous Agents and MultiAgent Systems, Stockholm, Sweden, 10-15 July 2018; International Foundation for Autonomous Agents and Multiagent Systems: Richland, SC, USA, 2018; pp. $2236-2238$.

85. Barange, M.; Saunier, J.; Pauchet, A. Pedagogical Agents as Team Members: Impact of Proactive and Pedagogical Behavior on the User. In Proceedings of the AAMAS '17: 16th Conference on Autonomous Agents and MultiAgent Systems, São Paulo, Brazil, 8-12 May 2017; International Foundation for Autonomous Agents and Multiagent Systems: Richland, SC, USA, 2017; pp. 791-800.

86. Fukuda, M.; Huang, H.H.; Nishida, T. Investigation of Class Atmosphere Cognition in a VR Classroom. In Proceedings of the HAI 2018 -6th International Conference on Human-Agent Interaction, Southampton, UK, 15-18 December 2018; Association for Computing Machinery: New York, NY, USA, 2018; pp. 374-376.

87. Blankendaal, R.A.; Bosse, T. Using Run-Time Biofeedback During Virtual Agent-Based Aggression De-escalation Training. In Proceedings of the Advances in Practical Applications of Agents, Multi-Agent Systems, and Complexity: The PAAMS Collection, 16th International Conference, PAAMS 2018, Toledo, Spain, 20-22 June 2018; Demazeau, Y., An, B., Bajo, J., Fernández-Caballero, A., Eds.; Springer: Cham, Switzerland, 2018; pp. 97-109. 
88. Feng, D.; Jeong, D.; Krämer, N.; Miller, L.; Marsella, S. Is It Just Me?: Evaluating Attribution of Negative Feedback as a Function of Virtual Instructor's Gender and Proxemics. In Proceedings of the AAMAS '17: 16th Conference on Autonomous Agents and MultiAgent Systems, São Paulo, Brazil, 8-12 May 2017; International Foundation for Autonomous Agents and Multiagent Systems: Richland, SC, USA, 2017; pp. 810-818.

89. Johnson, E.; Gratch, J.; DeVault, D. Towards An Autonomous Agent That Provides Automated Feedback on Students' Negotiation Skills. In Proceedings of the AAMAS '17: 16th Conference on Autonomous Agents and MultiAgent, São Paulo, Brazil, 8-12 May 2017; International Foundation for Autonomous Agents and Multiagent Systems: Richland, SC, USA, 2017 ; pp. 410-418.

90. Tavcar, A.; Gams, M. Surrogate-agent modeling for improved training. Eng. Appl. Artif. Intell. 2018, 74, 280-293. [CrossRef]

91. Barthès, J.P.A.; Wanderley, G.M.P.; Lacaze-Labadie, R.; Lourdeaux, D. Designing training virtual environments supported by cognitive agents. In Proceedings of the 2018 IEEE 22nd International Conference on Computer Supported Cooperative Work in Design (CSCWD), Nanjing, China, 9-11 May 2018; Shen, W., Luo, J., Bartgès, J.P., Dong, F., Zhang, J., Zhu, H., Eds.; IEEE: New York, NY, USA, 2018; pp. 295-300.

92. De Lima, R.M.; De Medeiros Santos, A.; Mendes Neto, F.M.; França de Sousa Neto, A.; Leão, F.C.P.; de Macedo, F.T.; de Paula Canuto, A.M. A 3D serious game for medical students training in clinical cases. In Proceedings of the 2016 IEEE International Conference on Serious Games and Applications for Health (SeGAH), Orlando, FL, USA, 11-13 May 2016; IEEE: New York, NY, USA, 2016; pp. 1-9.

93. Benkhedda, S.; Bendella, F. FASim: A 3D Serious Game for the First Aid Emergency. Simul. Gaming 2019, 50, 690-710. [CrossRef]

94. Ooi, S.; Tanimoto, T.; Sano, M. Virtual Reality Fire Disaster Training System for Improving Disaster Awareness. In Proceedings of the ICEIT 2019: Proceedings of the 2019 8th International Conference on Educational and Information Technology, Cambridge, UK, 2-4 March 2019; Association for Computing Machinery: New York, NY, USA, 2019; pp. 301-307.

95. Tianwu, Y.; Changjiu, Z.; Jiayao, S. Virtual Reality Based Independent Travel Training System for Children with Intellectual Disability. In Proceedings of the UKSim-AMSS 2016: 10th European Modelling Symposium on Computer Modelling and Simulation, Pisa, Italy, 28-30 November 2016; IEEE: New York, NY, USA, 2016; pp. 143-148.

96. Best, A.; Narang, S.; Manocha, D. SPA: Verbal Interactions between Agents and Avatars in Shared Virtual Environments using Propositional Planning. In Proceedings of the 020 IEEE Conference on Virtual Reality and 3D User Interfaces (VR), Atlanta, GA, USA, 22-26 March 2020; IEEE: New York, NY, USA, 2020.

97. Braz, P.; Werneck, V.M.B.; de Souza Cunha, H.; da Costa, R.M.E.M. SMEC-3D: A Multi-agent 3D Game to Cognitive Stimulation. In Proceedings of the Highlights of Practical Applications of Agents, Multi-Agent Systems, and Complexity: The PAAMS Collection, International Workshops of PAAMS 2018, Toledo, Spain, 20-22 June 2018; Bajo, J., Corchado, J.M., Navarro Martínez, E.M., Osaba Icedo, E., Mathieu, P., Hoffa-Dąbrowska, P., del Val, E., Giroux, S., Castro, A.J., Sánchez-Pi, N., et al. Eds.; Springer: Cham, Switzerland, 2018; pp. 247-258.

98. Christian, J.; Hansun, S. Simulating Shopper Behavior using Fuzzy Logic in Shopping Center Simulation. J. ICT Res. Appl. 2016, 10, 277-295. [CrossRef]

99. Zhao, Y.; Pour, F.; Golestan, S.; Stroulia, E. BIM Sim/3D: Multi-Agent Human Activity Simulation in Indoor Spaces. In Proceedings of the 2019 IEEE/ACM 5th International Workshop on Software Engineering for Smart Cyber-Physical Systems (SEsCPS), Montreal, QC, Canada, 25-31 May 2019; IEEE: New York, NY, USA, 2019; pp. 18-24.

100. Vosinakis, S.; Avradinis, N.; Koutsabasis, P. Dissemination of Intangible Cultural Heritage Using a Multi-agent Virtual World. In Proceedings of the Dvances in Digital Cultural Heritage, International Workshop, Funchal, Madeira, Portugal, 28 June 2017; Ioannides, M., Martins, J., Žarnić, R., Lim, V., Eds.; Springer: Cham, Switzerland, 2018; Volume 10754, pp. $197-207$.

101. Kiourt, C.; Pavlidis, G.; Koutsoudis, A.; Kalles, D. Multi-agents based virtual environments for cultural heritage. In Proceedings of the 2017 XXVI International Conference on Information, Communication and Automation Technologies (ICAT), Sarajevo, Bosnia-Herzegovina, 26-28 October 2017; IEEE: New York, NY, USA, 2017; pp. 1-6.

102. Ren, J.; Xiang, W.; Xiao, Y.; Yang, R.; Manocha, D.; Jin, X. Heter-Sim: Heterogeneous multi-agent systems simulation by interactive data-driven optimization. IEEE Trans. Vis. Comput. Graph. 2019, 27, 1953-1966. [CrossRef] [PubMed]

103. Rivalcoba, I.; Toledo, L.; Rudomín, I. Towards urban crowd visualization. Sci. Vis. 2019, 11, 39-55. [CrossRef]

104. Okamoto, S.; Takematsu, S.; Matsumoto, S.; Otabe, T.; Tanaka, T.; Tokuyasu, T. Development of Design Support System of a Lane for Cyclists and Pedestrians. In Proceedings of the 2016 10th International Conference on Complex, Intelligent, and Software Intensive Systems (CISIS), Fukuoka, Japan, 6-8 July 2016; Barolli, L., Xhafa, F., Ikeda, M., Eds.; IEEE: New York, NY, USA, 2016; pp. 385-388.

105. Chen, A.Y.; Chen, J.H. Urban rail transit operation simulation based on virtual reality technology. In Proceedings of the 17th COTA International Conference of Transportation Professionals, Shanghai, China, 7-9 July 2017; ASCE: Reston, VA, USA, 2017; pp. 1736-1745.

106. Garg, D.; Chli, M.; Vogiatzis, G. Traffic3D: A new traffic simulation paradigm. In Proceedings of the AAMAS '19: Proceedings of the 18th International Conference on Autonomous Agents and MultiAgent Systems, Montreal, QC, Canada, 13-17 May 2019; International Foundation for Autonomous Agents and Multiagent Systems: Richland, SC, USA, 2019; pp. $2354-2356$.

107. Chen, Y.; Chen, S.; Zhang, T.; Zhang, S.; Zheng, N. Autonomous Vehicle Testing and Validation Platform: Integrated Simulation System with Hardware in the Loop*. In Proceedings of the 2018 IEEE Intelligent Vehicles Symposium (IV), Changshu, China, 26-30 June 2018; IEEE: New York, NY, USA, 2018; pp. 949-956. 
108. Elmquist, A.; Hatch, D.; Serban, R.; Negrut, D. An overview of a Connected Autonomous Vehicle Emulator (CAVE). In Proceedings of the ASME 2017 International Design Engineering Technical Conferences and Computers and Information in Engineering Conference, Cleveland, OH, USA, 6-9 August 2017; ASME: New York, NY, USA, 2017; pp. 1-12.

109. Ďurica, L.; Gregor, M.; Vavrík, V.; Marschall, M.; Grznár, P.; Mozol, Š. A Route Planner Using a Delegate Multi-Agent System for a Modular Manufacturing Line: Proof of Concept. Appl. Sci. 2019, 9, 4515. [CrossRef]

110. Xie, J.; Yang, Z.; Wang, X.; Zeng, Q.; Li, J.; Li, B. A Virtual Reality Collaborative Planning Simulator and Its Method for Three Machines in a Fully Mechanized Coal Mining Face. Arab. J. Sci. Eng. 2018, 43, 4835-4854. [CrossRef]

111. Wang, Y.; Lv, C.; Zhou, D.; Yu, D.; Peng, X. Multi-agent based modeling and simulation of virtual maintenance system. In Proceedings of the 2016 12th World Congress on Intelligent Control and Automation (WCICA), Guilin, China, 12-15 June 2016; IEEE: New York, NY, USA, 2016; pp. 2963-2968.

112. Bosse, T.; Hartmann, T.; Blankendaal, R.; Dokter, N.; Otte, M.; Goedschalk, L. Virtually Bad: A Study on Virtual Agents that Physically Threaten Human Beings. In Proceedings of the AAMAS '18: 17th International Conference on Autonomous Agents and MultiAgent Systems, Stockholm, Sweden, 10-15 July 2018; International Foundation for Autonomous Agents and Multiagent Systems: Richland, SC, USA, 2018; pp. 1258-1266. 